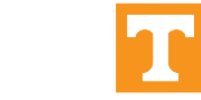

THE UNIVERSITY OF

TENNESSEE

KNOXVILLE

\title{
Enforcement spillovers: Lessons from strategic interactions in regulation and product markets
}

\author{
Mary F. Evans, Scott M. Gilpatric, and Jay P. Shimshack \\ August 2015
}

WORKING PAPER \#2015-08

\author{
WORKING PAPER SERIES \\ DEPARTMENT OF ECONOMICS \\ HASLAM COLLEGE OF BUSINESS \\ http://econ.bus.utk.edu
}

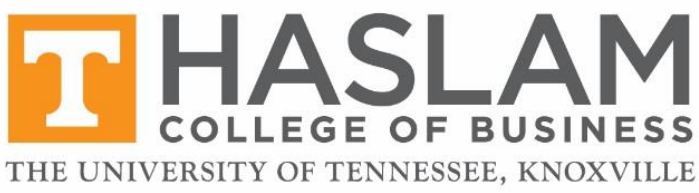




\title{
Enforcement spillovers: Lessons from strategic interactions in regulation and product markets
}

\author{
Mary F. Evans ${ }^{1}$, Scott M. Gilpatric ${ }^{2}$, and Jay P. Shimshack ${ }^{3}$
}

August 26, 2015

\begin{abstract}
We explore mechanisms driving enforcement spillovers - when sanctions at one entity influence behavior at other entities. Our model illustrates when spillovers arise from a regulatory channel and when they arise from a channel not emphasized in the existing literature: product markets. Using facility-by-month data from Clean Water Act manufacturers, we find that penalties generate strong positive spillovers for other facilities facing the same authority. We find suggestive evidence that penalties generate negative spillovers for facilities in the same industry but facing a different authority. Results are consistent with spillovers driven by strategic interactions in both regulation and product markets.
\end{abstract}

KEYWORDS: general deterrence, strategic substitutes, strategic complements, pollution policy

JEL CODES: K42, L51, Q58

\footnotetext{
${ }^{1}$ Corresponding author: The Robert Day School of Economics and Finance, Claremont McKenna College, 500 East Ninth Street, Claremont, CA 91711; 909.607.3423; mevans@cmc.edu.

${ }^{2}$ Department of Economics, University of Tennessee, sgilpatr@utk.edu

${ }^{3}$ Frank Batten School of Leadership and Public Policy, University of Virginia, jay.shimshack@virginia.edu
} 


\section{Introduction}

Without enforcement, regulations are just discretionary guidelines.

Philosophers have studied the public enforcement of law since Bentham (1789) and economists have formally proposed theories of punishment since at least Becker (1968) and Stigler (1970). ${ }^{1}$ Empirical evidence shows that inspections and sanctions can deter harm in regulatory settings as diverse as financial oversight; environmental, natural resource, and energy; food, drug, and occupational safety; and health administration [Cohen (1998); Baker (2003); Jackson and Roe (2009); Ruser and Ruser (2010); Leeth (2012); Gray and Shimshack (2011)]. Nonetheless, economists and policymakers still have an incomplete understanding of the mechanisms linking punishment with outcomes at regulated facilities. Of particular interest in this paper are the economic channels driving enforcement spillovers, the form of general deterrence that arises when sanctions levied against one entity "spill over" to influence behavior at other regulated entities. ${ }^{2}$

Such enforcement externalities have been documented for both individuals and firms. Empirical and experimental evidence shows that every dollar in revenue collected from an income tax audit spills over to generate many dollars in increased revenues from individuals not audited (Dubin et al. 1987, 1990; Alm 2012). Environmental compliance following water and air pollution enforcement activity increases almost as much at neighboring facilities as at penalized facilities (Shimshack and Ward 2005; Gray and Shadbegian 2007).

\footnotetext{
${ }^{1}$ Polinsky and Shavell (2000) survey this literature.

2 Other authors have used the phrases 'enforcement spillovers' or 'enforcement externalities' to describe geographic spillovers in criminal settings, where enforcement threats induce criminals to shift crime to other areas (e.g. Bronars and Lott 1998). This is not the subject of the present paper.
} 
Inspections for television license fees in Austria influenced compliance at noninspected households (Rincke and Traxler 2011).

The economic mechanism typically postulated to link enforcement actions directed towards one agent to the behavior of other agents is a reputational learning channel, following Sah's (1990) work on social osmosis in crime. In an uncertain regulatory environment, potential violators update beliefs about their own expected penalties based on recent experiences of those around them. In the regulatory context, direct regulatory spillovers inherently arise. Heyes and Kapur (2009) develop a model in which regulatory actions at one facility have implications for actions at other facilities, the nature of which depends upon the particular strategy adopted by the regulatory agency. ${ }^{3}$ If enforcement actions against one facility foster a "regulator reputation" for toughness, positive regulatory spillovers arise (Shimshack and Ward 2005, 2008; Rincke and Traxler 2011). ${ }^{4}$ If enforcement actions against one facility reduce enforcement resources available for targeting other facilities, negative regulatory spillovers arise (Heyes and Kapur 2009).

This paper's point of departure is the simple observation that, in regulatory contexts, enforcement spillovers may also be attributable to a mechanism not emphasized in the existing enforcement literature: strategic interactions in product markets. If two plants produce strategic substitutes so that less aggressive strategies by one increase marginal profits of the other, then

\footnotetext{
${ }^{3}$ Heyes and Kapur (2009) are primarily concerned with optimal regulator behavior under different enforcement missions. Although we draw from their model, our paper has fundamentally different research questions and objectives.

${ }^{4}$ In Heyes and Kapur (2009)'s model, positive regulatory spillovers arise when the regulator's objective is to achieve a particular level of aggregate environmental quality at least enforcement cost (i.e., his mission is "target-driven"). When the regulator uncovers a violation at a particular facility (which then necessitates an enforcement action against that facility), he is further from his goal and therefore must become "tougher" on other facilities.
} 
enforcement actions levied against one plant may increase output and externalities at the other plant. Similarly, if two plants produce strategic complements so that less aggressive strategies by one reduce marginal profits of the other, then enforcement actions levied against one plant may reduce optimal output and externalities at the other plant. In both scenarios, enforcement spillovers arise even in the absence of strategic interactions in the regulatory environment.

We first develop a new enforcement and compliance model that formalizes facilities' interactions in both the output market and in the regulatory environment. For tractability and to match our later empirical setting, we emphasize the implications of these two channels of interactions for facilities' optimal levels of a pollution externality. Our stylized two-facility framework allows one plant's revenue to depend on its own output and the output of the other plant. In the spirit of Bulow, Geanakoplos, and Klemperer (1985), we allow one facility's actions in its output market to change another facility's strategies via changes in marginal benefits of production. Building from Heyes and Kapur (2009), we also allow a regulator's actions against one facility to directly influence the perceived regulatory scrutiny for the other facility via changes in marginal expected penalties. An innovation of our model is the combination of these effects to help understand when and how enforcement spillovers might arise. To be precise, a key novel feature of our model is that enforcement spillovers can be driven by interactions in the regulatory environment, in the output product market, or both. We derive comparative static results that highlight the link between the presence and strength of strategic interactions through these two channels and the sign and magnitude of overall enforcement spillovers. 
We then use evidence from the Clean Water Act (CWA) to empirically investigate testable hypotheses motivated by our theory. We explore monthly enforcement, pollution, and compliance data for several hundred large U.S. manufacturers over many years. We examine relationships between pollution at a given facility and enforcement actions at other facilities following the related empirical general deterrence literature for regulatory settings. We flexibly control for facility-level, industry-level, community-level, seasonal, and economic confounders. By using rich facility-by-month data and panel data techniques, and by exploring the effects of actions at one facility on the subsequent behavior of other (not directly targeted) facilities, we avoid most common identification problems arising from the non-random assignment of enforcement. We address other endogeneity threats, including correlated demand shocks within an industry and correlated economic shocks within a given area, with empirical strategies that identify enforcement spillovers off of within state-year variation and within industry-year variation.

We find three main empirical results. First, we observe statistically significant and robust evidence that CWA enforcement actions spill over to reduce pollution at other facilities in the same industry and facing the same state regulatory authority. These positive enforcement spillovers are most consistent with a strong regulator reputation mechanism swamping likely countervailing product market mechanisms. Second, we find statistically significant evidence that CWA enforcement actions also spill over to reduce pollution at other facilities in different industries as long as those facilities face the same state regulator. Again, these positive enforcement spillovers are most likely driven by a strong regulator reputation channel. Third, we find suggestive but somewhat less robust evidence that CWA enforcement actions spill over to increase 
pollution at facilities in the same industry but facing a different regulatory authority. These negative enforcement externalities are consistent with strategic product market interactions driving some observed spillovers.

We believe our analysis makes several contributions to economics and policy. Relative to the existing literature, we propose a more general model of strategic interactions between producers. We analytically demonstrate that enforcement spillovers previously attributed to regulatory interaction channels could arise from product market interaction channels. We then use a rich dataset to show empirically that both large positive enforcement spillovers and small negative enforcement spillovers arise from CWA actions. We are able to more completely characterize the economic mechanisms for empirically detected positive spillovers than earlier literature. The negative spillover result is new to the empirical literature.

One policy implication echoes conclusions from the existing literature: regulator's enforcement actions appear to have a multiplier effect within the same regulatory jurisdiction, an effect that is further amplified among facilities also in the same industry. As such, the bang per buck from enforcement actions is larger than expected when considering effects on the sanctioned facility alone. A more cautionary policy implication arises from negative enforcement spillovers. Enforcement actions appear to generate a form of unintended "leakage" for facilities in the same industry but located in other regulatory jurisdictions. Despite an increasing understanding of emissions leakage stemming from partial regulatory designs in pollution markets (Fowlie 2009, Bushnell and Mansur 2011, Baylis et al. 2014), we believe this is the first paper to directly demonstrate leakage from regulatory enforcement. 


\section{Modeling enforcement spillovers}

\section{A. Setup}

We propose a duopoly model in which each facility $i=A, B$ chooses output and emissions, denoted $q_{i}$ and $e_{i}$, respectively to maximize expected profit. Expected profit depends on revenues, production costs, and expected regulatory costs. Facility i's revenues vary with its own output as well as (potentially) the output of the other facility, $q_{-i}$. We denote facility i's revenue function as $R_{i}=R_{i}\left(q_{i}, q_{-i}\right)$ and assume $\frac{\partial R_{i}}{\partial q_{i}}>0, \frac{\partial^{2} R_{i}}{\partial q_{i}{ }^{2}}<0$. Plant i's production costs depend on its own output and emissions and are denoted $C_{i}=C_{i}\left(q_{i}, e_{i}\right)$, where we assume $\frac{\partial C_{i}}{\partial q_{i}}>0, \frac{\partial^{2} C_{i}}{\partial q_{i}{ }^{2}}>0, \frac{\partial C_{i}}{\partial e_{i}}<0, \frac{\partial^{2} C_{i}}{\partial e_{i}{ }^{2}}>0, \frac{\partial^{2} C_{i}}{\partial q_{i} \partial e_{i}}<0$. Facility i's expected regulatory costs are a function of its emissions, the regulatory pressure it faces, and possibly the regulatory pressure faced by the other facility. The parameters $\rho_{A}$ and $\rho_{B}$ denote the regulatory pressure faced by facilities A and B, respectively. The regulatory cost function for $i$ is given by $F_{i}=F_{i}\left(e_{i}, \rho_{i}, \rho_{-i}\right)$. We assume $\frac{\partial F_{i}}{\partial e_{i}}>0, \frac{\partial^{2} F_{i}}{\partial e_{i}{ }^{2}} \geq 0, \frac{\partial^{2} F_{i}}{\partial e_{i} \partial \rho_{i}}>0$. The expected profit function for facility $i$ is then given by:

$$
\pi_{i}=R_{i}\left(q_{i}, q_{-i}\right)-C_{i}\left(q_{i}, e_{i}\right)-F_{i}\left(e_{i}, \rho_{i}, \rho_{-i}\right) .
$$

Our formulation, motivated by Bulow et al. (1985) and Heyes and Kapur (2009), allows for the possibility that the two plants interact through up to two channels (i) the product market (i.e., if $\frac{\partial^{2} R_{i}}{\partial q_{i} \partial q_{-i}} \neq 0$ ), and (ii) the regulatory environment (i.e., if $\frac{\partial^{2} F_{i}}{\partial e_{i} \partial \rho_{-i}} \neq 0$ ). By definition, facilities $A$ and $B$ produce strategic complements if $\frac{\partial^{2} R_{i}\left(q_{i}, q_{-i}\right)}{\partial q_{i} \partial q_{-i}}>0$ and strategic substitutes if $\frac{\partial^{2} R_{i}\left(q_{i}, q_{-i}\right)}{\partial q_{i} \partial q_{-i}}<$ 0 for $i=A, B$. We characterize interactions through the regulatory channel as 
either positive regulatory spillovers, which occur if $\frac{\partial^{2} F_{i}\left(e_{i}, \rho_{i}, \rho_{-i}\right)}{\partial e_{i} \partial \rho_{-i}}>0$, or negative regulatory spillovers, which arise when $\frac{\partial^{2} F_{i}\left(e_{i}, \rho_{i}, \rho_{-i}\right)}{\partial e_{i} \partial \rho_{-i}}<0$ for $i=A, B$. For

example, positive regulatory spillovers might arise when enforcement actions against one facility signal a regulator's reputation for toughness and negative regulatory spillovers might arise when enforcement actions against one facility reduce enforcement resources for targeting other facilities.

The following first order conditions, which characterize the optimal levels of output and emissions for the two facilities, must be satisfied at an interior Nash equilibrium:

$$
\begin{aligned}
& h_{1} \equiv \frac{\partial \pi_{A}}{\partial q_{A}}=\frac{\partial R_{A}}{\partial q_{A}}-\frac{\partial C_{A}}{\partial q_{A}}=0 \\
& h_{2} \equiv \frac{\partial \pi_{A}}{\partial e_{A}}=-\frac{\partial C_{A}}{\partial e_{A}}-\frac{\partial F_{A}}{\partial e_{A}}=0 \\
& h_{3} \equiv \frac{\partial \pi_{B}}{\partial q_{B}}=\frac{\partial R_{B}}{\partial q_{B}}-\frac{\partial C_{B}}{\partial q_{B}}=0 \\
& h_{4} \equiv \frac{\partial \pi_{B}}{\partial e_{B}}=-\frac{\partial C_{B}}{\partial e_{B}}-\frac{\partial F_{B}}{\partial e_{B}}=0
\end{aligned}
$$

Let $\mathrm{H}$ denote the Hessian matrix of second-order partial derivatives. We assume the second-order conditions for maximization are satisfied and that $\mathrm{H}$ satisfies the property of diagonal dominance. ${ }^{5}$ Conditions (2) and (4) have the familiar interpretation that each facility's marginal revenues from production equal marginal costs of production at an optimum. Conditions (3) and (5) imply that each optimizing facility emits until the marginal benefits of polluting in terms of reduced production costs equal the marginal costs of polluting in terms of

\footnotetext{
${ }^{5} \mathrm{~A}$ matrix $\mathrm{M}$ satisfies diagonal dominance if its diagonal elements are such that $\left|M_{i i}\right|>\sum_{j \neq i}\left|M_{i j}\right|$ for all $i$ (Bulow et al. 1983).
} 
increased expected regulatory costs. In other words, this is the familiar Becker (1968) condition.

\section{B. Characterizing enforcement spillovers}

Our primary interest is characterizing the comparative static effects of increased regulatory pressure on facility A for outcomes at facility B. ${ }^{6}$ We use Cramer's Rule to solve for $\frac{\partial q_{B}}{\partial \rho_{A}}$ and $\frac{\partial e_{B}}{\partial \rho_{A}}$. An enforcement spillover arises whenever $\frac{\partial e_{B}}{\partial \rho_{A}}$ is non-zero. The following propositions illustrate the nature of our results. The appendix contains all proofs.

Proposition 1: If the two facilities produce strategic complements and face positive regulatory spillovers, then an increase in regulatory pressure on facility A reduces optimal output and emissions at facility B: $\frac{\partial q_{B}}{\partial \rho_{A}}$, $\frac{\partial e_{B}}{\partial \rho_{A}}<0$

Proposition 2: If the two facilities produce strategic substitutes and face negative regulatory spillovers, then an increase in regulatory pressure on facility $A$ increases optimal output and emissions for facility $\mathrm{B} ; \frac{\partial q_{B}}{\partial \rho_{A}}$, $\frac{\partial e_{B}}{\partial \rho_{A}}>0$

Corollary 1: If the two facilities produce strategic complements and face negative regulatory spillovers, or if they produce strategic substitutes and face positive regulatory spillovers, then an increase in regulatory pressure on facility $A$ has an ambiguous effect on output and emissions at facility B.

\footnotetext{
${ }^{6}$ Regulatory pressure at facility A, of course, also impacts outcomes at facility A itself. An earlier version of this paper derives these specific deterrence results, which are intuitive. We omit them here since they are not the focus of the paper.
} 
In the two cases addressed by Propositions 1 and 2, the incentives for facility $B$ that arise from increased regulatory pressure on facility $A$ through the product and regulatory channels reinforce each other. In the former case, positive enforcement spillovers (i.e., $\frac{\partial e_{B}}{\partial \rho_{A}}<0$ ) arise while in the latter case, negative enforcement spillovers (i.e., $\frac{\partial e_{B}}{\partial \rho_{A}}>0$ ) result. In the ambiguous cases covered by Corollary 1 , the sign of the effect of an increase in regulatory pressure is determined by the relative strength of the two channels of strategic interaction. For example, if the facilities produce strategic complements with negative regulatory spillovers but the former channel dominates, then an increase in regulatory pressure on facility $A$ reduces optimal output and emissions for facility $\mathrm{B}, \frac{\partial q_{B}}{\partial \rho_{A}}$, $\frac{\partial e_{B}}{\partial \rho_{A}}<0 .^{7}$

It is also illustrative to compare and contrast cases with and without product market spillovers, as well as cases with and without regulatory spillovers. To motivate our subsequent empirical setting, we focus on relationships between regulatory pressure at one facility and emissions outcomes at the other facility (i.e., the sign of $\frac{\partial e_{B}}{\partial \rho_{A}}$ ).

Proposition 3: For facilities that interact in the regulatory environment, the overall enforcement spillover effect when the facilities have independent demands is not equal to the overall spillover effect when facilities have interrelated demands.

\footnotetext{
${ }^{7}$ The next section considers a more structured version of our model, which allows us to further explore the ambiguous cases covered by Corollary 1.
} 
Proposition 4: For facilities that interact in the product market, the overall enforcement spillover effect when the facilities have no strategic interactions in the regulatory environment is not equal to the overall enforcement spillover effect when they do.

Propositions 1 to 4 and Corollary 1, while intuitive, are challenging to test directly. As noted by Bulow et al. (1985) and implied by Heyes and Kapur (2009), if and how facilities strategically interact in product markets and if and how regulatory spillovers occur across facilities are ultimately empirical questions in their own right. We note, however, that the model generates predictions for overall net enforcement spillovers given the direction and magnitude of interactions in product markets and regulatory environments. Table 1 summarizes all such predictions.

\section{Interpreting the model}

In this section, we use results from the existing literature to refine the general predictions that arise from our theoretical model. We focus on two main refinements, which are plausible a priori but remain empirically refutable. First, while our model allows for product market interactions to take the form of strategic substitutes or complements, we anticipate that facilities in the same industry will produce the former. Standard Cournot competition with linear demand yields strategic substitutes and Fowlie (2009) notes that many industrial product markets are reasonably characterized by the Cournot framework. For example, Bushnell et al. (2008) argue that Cournot assumptions capture key features of the electricity market after accounting for vertical arrangements. Simulation

To illustrate the implications of this first refinement, we simulate a Cournot duopoly with symmetric facilities facing linear demand as in Fowlie 
(2009). The simulation results demonstrate clearer testable implications for behavior that arise from our model when facilities produce strategic substitutes.

Normalize inverse demand to $P=1-Q$ where $Q=q_{A}+q_{B}$. Assume production costs for facility $i=A, B$ are $C_{i}\left(q_{i}, e_{i}\right)=\frac{q_{i}^{2}}{e_{i}}$ and define facility i's emissions per unit of output as $\varepsilon_{i}=\frac{e_{i}}{q_{i}}$. Given this cost function, facility $i$ has constant production costs per unit of output equal to $\frac{1}{\varepsilon_{i}}$, which are obviously decreasing with $\varepsilon_{i}$. Let facility i's regulatory cost function be parameterized as $F_{i}\left(e_{i}, \rho_{i}, \rho_{-i}\right)=e_{i}\left(\rho_{i}+\beta \rho_{-i}\right)$ where $\beta \in(-1,1] .{ }^{8}$ The sign and magnitude of $\beta$ indicate the nature and strength of regulatory spillovers with positive values of $\beta$ close to 1 for strong positive spillovers and negative values of $\beta$ close to -1 for strong negative spillovers.

With this structure, facility i's profit function is given by

$$
\pi_{i}=\left(1-q_{i}-q_{-i}\right) q_{i}-\frac{q_{i}^{2}}{e_{i}}-e_{i}\left(\rho_{i}+\beta \rho_{-i}\right) .
$$

This model yields a convenient analytical solution of the following form:

$$
\begin{gathered}
q_{i}=\frac{1}{3}+\frac{2}{3} \sqrt{\left(\rho_{-i}+\beta \rho_{i}\right)}-\frac{4}{3} \sqrt{\left(\rho_{i}+\beta \rho_{-i}\right)} \\
e_{i}=\frac{q_{i}}{\sqrt{\left(\rho_{i}+\beta \rho_{-i}\right)}} .
\end{gathered}
$$

We assume initial values of $\rho_{A}$ and $\rho_{B}$ of 0.10 .

Our simulation results illustrate the effects of a $10 \%$ increase in regulatory pressure on facility A (i.e., a $10 \%$ increase in $\rho_{A}$ ) on both facilities' optimal levels of output, emissions, and emissions per unit of output under

\footnotetext{
${ }^{8}$ Note that in this structure $\rho_{i}+\beta \rho_{-i}$ (the cost of emitting) would become less than or equal to zero for some parameter values, which we assume do not hold. It is for this reason that we assume $\beta>-1$, because for $\beta=-1$ the cost of emitting would be zero for both facilities under any symmetric enforcement, $\rho_{A}=\rho_{B}$.
} 
varying parameter values for $\beta .{ }^{9}$ We focus our discussion on the results most germane to our empirical analysis - the total enforcement spillover effect (i.e., the effect on facility B's emissions). Because of its policy relevance, we also consider the implications for total industry emissions (i.e., $E \equiv e_{A}+e_{B}$ ).

With no regulatory spillovers (i.e., $\beta=0$ ), the effects of increased regulatory pressure on facility $A$ are driven entirely by the facilities' interactions in the product market. Because the facilities produce strategic substitutes, an increase in $\rho_{A}$ from 0.10 to 0.11 decreases emissions for facility $A$ but increases emissions for facility B. In this benchmark simulation, total industry emissions (i.e., $E \equiv e_{A}+e_{B}$ ) fall by about 0.05 units as the reduction in facility A's emissions exceeds the increase in facility B's emissions. When facilities produce strategic substitutes, the net effect on total emissions of an asymmetric increase in regulatory pressure is akin to the effect of partial regulation (i.e, regulating only facility A) -the net effect on total emissions is smaller than if the facilities produced unrelated products (i.e., than if we ignore strategic interactions in the product market). Thus, our simulation with $\beta=0$ yields insights that are akin to Fowlie's finding of emissions leakage in the presence of partial regulation.

With non-zero values of $\beta$, the net effects of increased regulatory pressure on one facility are driven by the joint impacts of the two channels of strategic interactions. Figure 1 illustrates the percentage changes in $e_{B}$ and $E$ that result from a $10 \%$ increase in $\rho_{A}$ for different values of $\beta$. The dashed line represents the percentage change in $e_{B}$ and the solid line the percentage change in total industry emissions. As in the benchmark case with no regulatory spillovers, facility $\mathrm{B}$ increases its emissions in response to the increase in $\rho_{A}$ provided $\beta$ is less than about 0.4 . For values of $\beta$ that exceed this, the effect of

\footnotetext{
${ }^{9}$ Full simulation results are available by request.
} 
positive regulatory spillovers dominates the effect of strategic substitutes and both facilities reduce emissions in response to increased pressure on facility $A{ }^{10}$

Negative regulatory spillovers reinforce the effects of strategic substitutes so that facility $B$ increases emissions in response to an increase in $\rho_{A}$. In this case, the effect of an increase in $\rho_{A}$ on total emissions depends on the relative strengths of the two channels of strategic interactions. With weak negative regulatory spillovers (i.e., values of $\beta$ less than zero but greater than about -0.6), the reduction in $e_{A}$ dominates the increase in $e_{B}$ and the net effect on total emissions is negative. When regulatory spillovers are strongly negative (i.e., for values of $\beta$ less than about -0.6), the increase in $e_{B}$ more than offsets the decrease in $e_{A}$ so that the net effect on total emissions is positive; that is, increased regulatory pressure on facility A actually increases total emissions.

\section{Empirically testable predictions}

As illustrated in Figure 1, our theory accommodates positive and negative regulatory spillovers but what are our expectations about the true nature of regulatory spillovers (e.g., the true value of $\beta$ )? Our second refinement relates to this issue. Based on prior empirical evidence, we expect facilities facing the same primary regulatory authority to experience positive regulatory spillovers (Shimshack and Ward 2005, 2008; Gray and Shadbegian 2007; Rincke and Traxler 2011).

These refinements, along with the assumptions that (1) strategic interactions in the product market are confined to facilities in the same industry and (2) strategic interactions in the regulatory environment are confined to facilities facing the same primary regulatory authority, lead to the following

\footnotetext{
${ }^{10}$ The increase in regulatory pressure on facility A causes facility $A$ to reduce emissions for all values of $\beta$ although larger values of $\beta$ dampen the magnitude of the effect.
} 
empirical predictions about enforcement spillovers. Recall that an enforcement spillover is positive if a facility decreases its emissions in response to increased regulatory pressure on another facility.

Prediction 1: Facilities in different industries and facing the same primary regulatory authority will experience positive overall enforcement spillovers.

Prediction 1a: Overall enforcement spillovers for facilities in the same industry and facing the same primary regulatory authority will not equal overall enforcement spillovers for facilities in different industries and facing the same primary regulatory authority.

Prediction 2: Facilities in the same industry and facing different primary regulatory authorities will experience negative overall enforcement spillovers.

Prediction 2a: Overall enforcement spillovers for facilities in the same industry and facing the same primary regulatory authority will not equal overall enforcement spillovers for facilities in the same industry and facing different primary regulatory authorities.

Prediction 3: Facilities in the same industry and facing the same primary regulatory authority will experience positive overall enforcement spillovers if regulatory channels dominate product market channels.

Prediction 1 follows from our discussion above and the definition of positive regulatory spillovers given the absence of the product market channel.

Prediction 1a follows from Proposition 3. Prediction 2 follows from the definition of strategic substitutes, as the regulatory spillover channel is absent. Prediction 2a follows from Proposition 4. Prediction 3 follows from Corollary 1 and its proof. 


\section{Empirical setting and data}

\section{A. Clean Water Act enforcement}

We test our empirical predictions using pollution, compliance, and enforcement data for a sample of large industrial facilities regulated under the U.S. Clean Water Act (CWA). To understand our empirical framework, it's helpful to briefly characterize Clean Water Act enforcement in the U.S. ${ }^{11}$ Three features of the CWA enforcement environment are particularly relevant for our empirical analysis.

First, the CWA enforcement environment makes it extremely unlikely that facilities in different states interact with the same primary regulator. Thus, our empirical analysis defines regulatory jurisdictions by state. Although legislation and guidance is largely set at the federal level, the overwhelming majority of permitting, enforcement, and monitoring activity is delegated to states or local authorities. State regulators with 'primacy' conduct the bulk of inspections and issue the bulk of enforcement actions under the CWA. ${ }^{12}$ State agencies are required to provide certain data to regional and federal EPA offices for review and, although legally possible, revocation of CWA primacy does not happen in practice. Regional and federal interventions in state efforts to enforce the CWA are especially rare for the large industrial facilities in our empirical sample.

For large facilities regulated under the Clean Water Act, monitoring takes several forms. The primary monitoring strategy relies on self-reported pollution discharges, and researchers and policy-makers typically assume self-disclosed

\footnotetext{
${ }^{11}$ See Shimshack (2014) for detailed discussion of U.S. environmental monitoring and enforcement institutions.

12 In the few cases where states decline primary regulatory authority, or for a limited number of facilities and industries, EPA offices conduct their own inspections and issue their own sanctions.
} 
discharges are reliable on average. Theory suggests well-designed self-reporting schemes will be incentive compatible (Kaplow and Shavell 1994), and independent government reviews and a growing empirical literature fail to reject the accuracy of large facilities' CWA self-reports (U.S. EPA 1999; Laplante and Rilstone 1996; Shimshack and Ward 2005; Chakraborti and Shimshack 2012). A likely reason is that sanctions for intentional misreporting are severe, and may include incarceration for both employees and managers (UhImann 2009). In contrast, penalties for typical violations of permitted pollution limits are relatively modest and do not involve incarceration (Shimshack 2014). Regulator inspections serve to verify the accuracy of self-reporting, identify easily correctable problems, and support enforcement actions. Inspections can vary from brief reconnaissance inspections that visually examine effluents to rigorous, weeks-long compliance evaluations involving sampling, equipment evaluations, and record-keeping reviews.

Enforcement actions for pollution violations can vary from informal phone calls to formal actions including civil litigation. Most formal enforcement actions are administrative orders, which may or may not be accompanied by monetary penalties. Although administrative sanctions can include field citations in some states, the bulk of these actions are issued by state or regional administrative law judges. Administrative sanctions can be imposed for paperwork or reporting errors, but the large majority at least partially address pollution violations. Sanctions may address multiple pollutants and violations simultaneously.

A second key feature of our CWA setting is regulatory discretion. Discretion is pronounced because resources are scarce, regulations and enforcement actions are technically and legally complex, and political economic 
factors are influential. The frequency and severity of CWA inspections and sanctions vary substantially across states and over time, even conditional on facility and pollution composition (U.S. GAO 2009). According to federal enforcement guidelines all violations are supposed to be formally sanctioned. Penalty severity is intended to be a function of harm, financial gain from noncompliance, the violator's compliance and enforcement history, the facilities' ability to pay, and intent (U.S. EPA 1989). In practice, many violations are not sanctioned. Typical penalty magnitudes are small fractions of penalties allowed under the statute and are highly variable.

The third key feature of the CWA enforcement environment is the observability of financial penalties and other significant sanctions to other (i.e., non-sanctioned) facilities and stakeholders. Enforcement authorities publicize penalties, trade journals summarize regulator actions and cases, and facilities informally interact with one another. Qualitative surveys of compliance officials (i.e., at industrial facilities) indicate an awareness of enforcement actions at other industrial facilities among most (as much as 90\%) respondents (Carlough 2004; Thornton et al. 2005). This awareness is a necessary, but not sufficient, condition for us to empirically observe the types of enforcement spillovers we model theoretically.

\section{B. Data}

Our specific data sources are the Environmental Protection Agency's Integrated Compliance Information System and the Permit Compliance System. These databases track monthly facility-level self-reported discharges, permitted pollution limitations, inspections, and enforcement actions under the Clean Water Act. We focus on the conventional water pollutant total suspended solids (TSS) (EPA parameter 00530), as it is the pollution parameter most consistently 
measured, tracked, and reported monthly across a large number of industries. ${ }^{13}$ TSS is also highly correlated with other conventional pollutants, toxics, and other contaminants like nutrients.

We first select all "major" manufacturing facilities in the continental United States with continuously active CWA permits between January 1996 and May 2006. Our pollution and compliance analysis period is the 101 months spanning January 1998 to May 2006, so a full analysis period beginning in 1996 allows two years of enforcement lags. ${ }^{14}$ We focus on major (i.e., large) facilities because non-majors are not required to report pollution and compliance outcomes every month, and because states are not required to input monitoring, enforcement, and compliance information into EPA databases for non-major facilities. Manufacturing facilities represent the bulk of major CWA facilities other than wastewater treatment plants, which are typically publicly owned and do not interact in product markets.

Since a key goal of our analysis is to examine spillovers within and across industries, we focus on facilities in industries with many major facilities and substantial water pollution impacts. Our final sample therefore contains facilities from the pulp and paper, inorganic chemicals, organic chemicals, petroleum refining, and steel industries. Four 2-digit SIC code industries $(26,28,29,33)$ include six 3-digit SIC code industries $(261,262,281,286,291,331)$ and eleven four-digit SIC code industries (2611, 2621, 2812, 2813, 2816, 2819, 2861, 2865, $2869,2911,3312)$. Since our goals also involve an examination of spatial

\footnotetext{
${ }^{13}$ A supplemental analysis examines biochemical oxygen demand, a less consistently measured but still common conventional water pollutant.

${ }^{14}$ Time periods were chosen for data consistency. Reasonably high quality CWA discharges data became available in 1998. Data migration between data systems began in June 2006, and some pollution and compliance information was not consistently tracked in public EPA databases during migration periods.
} 
spillovers within and across state-level regulatory jurisdictions, we focus on states with reasonable numbers of CWA majors over the time period of our analysis. Since the majority of such states were in the eastern half of the country, our final sample includes states east of the Mississippi River plus the industrialized CWA states of Texas, Louisiana, and Oklahoma. ${ }^{15}$ For our empirical analysis, we define industries (i.e., product market interactions) by 3-digit SIC code largely for convenience, as this approach balances state and industry coverage. We later explore robustness of our results to an alternative industry definition.

\section{Analysis sample}

Our final sample consists of 491 large manufacturing facilities. The map in Figure 2 shows the locations of sample facilities. Facilities are somewhat clustered along major rivers and coasts, as perhaps expected. About 32\%, 15\%, $25 \%, 15 \%$, and $13 \%$ of facilities are associated with the pulp and paper; inorganic chemicals; organic chemicals; petroleum refining; and steel industries respectively.

The top panels of Table 2 summarize monitoring and enforcement actions at sample facilities. In an average month, about 10 percent of facilities received at least a reconnaissance inspection. All facilities except for one were inspected at least once during our sample period. 86 facilities received 144 fines over the enforcement sample period. The median fine was $\$ 11,500$, and fines were highly variable. Note that fine magnitudes should be interpreted relative to the economic gains from the specific triggering violation(s), rather than to operating profits of the facility itself. Moreover, the impact of fines may be

\footnotetext{
${ }^{15}$ The overwhelming majority of mid-western and western states had fewer than five CWA manufacturing majors. New Hampshire also had few CWA majors and is omitted.
} 
functionally larger than the penalty amount itself would suggest as the fine may leverage additional compliance channels like activist pressures, consumer pressures, and input market pressures. See, for example, Innes and Sam (2008), Bennear and Olmstead (2008), and Lyon and Maxwell (2012).

Fines enter our main empirical specifications through general deterrence spillover measures which indicate the number of fines at other facilities in various state-industry groups in the recent past. ${ }^{16}$ As indicated in the middle panels of Table 2, the mean number of fines on other facilities in the same state and 3-digit SIC industry in the previous year is 0.22 . The mean number of fines on other facilities in the same state but a different industry in the previous year is 0.57 . The mean number of fines on other facilities in the same industry but in a different state in the previous year is 2.33 .

Following the empirical environmental enforcement literature, our emissions measures are monthly average discharges expressed as the percent of permitted pollution (Earnhart 2004; Shimshack and Ward 2008). ${ }^{17}$ Violations occur when discharge ratios exceed one hundred percent. Our final analysis sample tracks TSS discharges from the 415 of 491 original sample facilities that reported TSS discharges for the majority of our pollution periods. Most of the 76 facilities with missing data were either not required to report TSS discharges or reported no TSS discharges during the sample period. A small number of facilities

\footnotetext{
${ }^{16}$ Our fines are administrative fines, which are formal administrative actions accompanied by monetary penalties, indicated in our databases as a non-zero value for "penalty amount assessed." This represents the dollar amount of the assessed penalty as identified in the final administrative order.

${ }^{17}$ To be precise, since some plants may have multiple outfalls, our unit of observation is the plant-by-month maximum of monthly average discharge ratios across all possible outfalls. In a given month, the large majority of facilities discharge our specific pollution parameters from a single specific outfall. These outfalls remain constant over time. It is extremely unlikely that this convenient aggregation biases results (Shimshack and Ward 2008).
} 
have unexplained missing data, but we are unable to predict missingness with any observable facility characteristic.

The bottom panels of Table 2 summarize sample pollution and compliance measures. Mean discharges for TSS pollution were about 28 percent of limits and the $25^{\text {th }}$ and $95^{\text {th }}$ percentiles were approximately 10 and 75 percent of the limits. These statistics suggest a high rate of average statutory compliance with permitted effluent limits, consistent with McClelland and Horowitz (1999) and Shimshack and Ward (2008). However, pollution discharges were highly variable, both across facilities and across time for the average given facility. ${ }^{18}$ In an average month, more than 1 percent of facilities were in violation. 126 facilities violated TSS standards 486 times during our sample period. The average violation was more than two times the permitted limit, and dozens of violations were more than 10 times permitted limits.

The long-term trend in pollution discharges during our sample period is downward. Mean TSS pollution was approximately 10-20 percent higher for the first few months of 1998 than for the same months in 2006. Pollution variability increased somewhat between 1998 and 2001, but modestly declined along with mean discharges beginning in 2002. Discharges as a percent of limits exhibited mild seasonality throughout the sample period, with scaled pollution about 10 percent higher in the late winter/early spring than in the late summer/early fall.

\section{Econometric framework}

Our econometric goal is to investigate the channels through which enforcement spillovers arise in our empirical setting. Our basic empirical strategy is to regress pollution at a given facility in a given month on several enforcement

\footnotetext{
${ }^{18}$ Theories emphasizing implications of stochastic discharges include Beavis and Walker (1983); Beavis and Dobbs (1987); Segerson (1988); Shimshack and Ward (2008).
} 
spillover measures. Coefficients on the enforcement measures represent the impact of marginal changes in enforcement activity directed towards other facilities in the recent past on the pollution decisions of the average nontargeted facility. Our primary dependent variable is total suspended solids (TSS) emissions at facility $i$ in month $t, e_{i t}$, expressed as a percent of permitted limits. We also explore sensitivity to a linear probability model where outcomes are defined by the $0 / 1$ indicator function for a violation at facility $i$ in month $t$, 1 [violation $\left.{ }_{i t}\right]$. Other robustness checks examine the same outcomes for a different common water pollutant measure, biochemical oxygen demand (BOD).

Our key explanatory variables are enforcement spillover measures, SPILLOVERS ${ }_{i t}$. These lagged enforcement measures represent the number of monetary penalties assessed at facilities other than $i$ in the 1 to 12 months preceding month $t$ and in the 13 to 24 months preceding month $t .{ }^{19}$ To match our empirically testable predictions, these explanatory variables include the number of fines at other facilities in the same state and industry in the 1 to 12 months preceding $t$, the number of fines at other facilities in the same state but different industry in the 1 to 12 months preceding $t$, and the number of fines at other facilities in the same industry but a different state in the 1 to 12 months preceding $t$. Measures for 13 to 24 month lags are similarly defined.

Control variables include a facility's own recent monitoring and enforcement actions, $l_{i t}$. The vector $l_{i t}$ includes indicators for: facility $i$ was inspected in the 1 to 12 months prior to $t$, facility $i$ was inspected in the 13 to 24 month prior to year $t$, facility $i$ was fined in the 1 to 12 months prior to $t$, and facility $i$ was fined in the 13 to 24 months prior to year $t$. We are not directly

\footnotetext{
${ }^{19}$ We choose the 1 year and 2 year lags following the empirical environmental enforcement literature (Gray and Deily 1996, Earnhart 2004; Shimshack and Ward 2005; Gray and Shadbegian 2005; Shimshack and Ward 2008).
} 
interested in causal interpretation of these specific deterrence measures. For this reason and due to possible endogeneity from regulator targeting, ${ }^{20}$ we include specific deterrence variables merely as controls. Additional controls are season-of-year dummies $\left(\mu_{s}\right)$, since both pollution and enforcement can vary seasonally, and year dummies $\left(\gamma_{y}\right)$ to control for economic and technological shocks common across all facilities.

In order to control for time invariant (or nearly so) facility characteristics, the empirical model includes facility-level fixed effects $\alpha_{\mathrm{i}}$. Facility-level fixed effects capture facility characteristics possibly correlated with both pollution and enforcement intensity like industry, subindustry, production capacity, and the biophysical conditions of the receiving waters and the surrounding area. Facilitylevel fixed effects also capture possible confounders associated with community characteristics like income, education, and political affiliations. Notably, facilitylevel fixed effects eliminate bias from enforcement targeting based on the average environmental performance of the facility, state, region, or industry. Identification is within-group.

For facility $i$ in month $t$ of season $s$ and year $y$, regressions take the general form:

$$
e_{i t}=\alpha_{i}+\text { SPILLOVERS }{ }_{i t} \beta+I_{i t} \delta+\mu_{s}+\gamma_{y}+\varepsilon_{i t} .
$$

Variable constructions, fixed effects, and control variables address many standard threats to plausible causal attribution. We attempt to minimize remaining endogeneity concerns with three empirical designs, each with its own strength and weaknesses. For facility $i$ in industry $k$ and state $j$, we augment regression (9) with facility-specific linear time trends $\rho_{i t}$ in specification (10),

\footnotetext{
${ }^{20}$ Facility $i$ is likely to be fined after periods of especially high pollution, and serially correlated pollution could bias coefficients on relationships between lagged fines and subsequent polluting behavior.
} 
facility-specific time trends and industry-by-year fixed effects $\theta_{i k t}$ in (11), and state-by-year fixed effects $\tau_{i j t}$ in (12) as follows:

$$
\begin{aligned}
& e_{i t}=\alpha_{i}+\text { SPILLOVERS } i t \beta+I_{i t} \delta+\mu_{s}+\gamma_{y}+\rho_{i t}+\varepsilon_{i t} . \\
& e_{i k t}=\alpha_{i}+\text { SPILLOVERS } i t \beta+I_{i t} \delta+\mu_{s}+\gamma_{y}+\rho_{i t}+\theta_{i k t}+\varepsilon_{i t} . \\
& e_{i j t}=\alpha_{i}+\text { SPILLOVERS } i t \beta+I_{i t} \delta+\mu_{s}+\gamma_{y}+\tau_{i j t}+\varepsilon_{i t} .
\end{aligned}
$$

Facility-specific time trends address variation in technology adoption and local economic trends across facilities. Industry-by-year fixed effects address common shocks within an industry that are correlated with both pollution and enforcement spillover measures. In specifications of the form (11), identification of $B$ comes from atypical deviations from industry-average enforcement activity for that same year (net of time invariant facility-level characteristics, seasonality, national economic and technological shocks, etc.). State-by-year fixed effects address common shocks within a state that are correlated with both pollution and enforcement spillover measures. ${ }^{21}$ In specifications of the form (12), identification of $B$ comes only from atypical deviations from state-average enforcement activity for that same year (again, net of time invariant facility-level characteristics, seasonality, national economic and technological shocks, etc.).

In our primary analysis, all standard errors are clustered at the statelevel. We later explore robustness to clustering at the facility-level and industrylevel. Collectively, these approaches address possible serial and spatial correlation.

\footnotetext{
${ }^{21}$ Since some states contain reasonably small numbers of facilities, state-by-year dummies and facility-specific trends were occasionally highly correlated. We thus omit facility-specific trends from regressions of the form (12).
} 


\section{$\underline{\text { V. Results }}$}

Table 3 presents estimated coefficients on the enforcement spillover measures associated with specifications (9)-(12). ${ }^{22}$ Before interpreting our key enforcement spillover results, we briefly note the impact of control variables. Consistent with summary statistics, pollution declines significantly over our sample period and is seasonal with highs in late winter and lows in the late summer and early fall. As expected, signs and significance on facility-level fixed effects and facility-specific time trends (when included) vary substantially across facilities. Idiosyncratic specific deterrence measures, like lagged own inspections and lagged own fines, are consistently negatively related to subsequent pollution but not typically statistically significant. ${ }^{23}$

\section{A. Estimated enforcement spillover effects}

Columns (1) - (4) of Table 3 present results from our preferred specifications. The first and second rows indicate that, on average, facilities' discharge ratios declined significantly in the years following fines on other facilities in the same state and industry. The coefficients in the first row indicate that TSS discharge ratios fell by 2.6 to 3.2 percentage points in the year following the marginal fine on other facilities in same state and industry. These results translate into around a 9 to 11 percent overall reduction relative to the mean discharge ratio. These general deterrence effects from fines in the same state and industry appear to decay over time; three of the four coefficients in the second row of Table 3 indicate that the fall in the discharge ratio was about 10 to

\footnotetext{
${ }^{22}$ Full regression results are available by request.

${ }^{23}$ These insignificant coefficients may represent truly small incremental deterrence effects from a facility's own enforcement and monitoring actions, at least conditional on general deterrence signals about overall regulator behavior. Or, small and insignificant negative specific deterrence coefficients may also suggest a positive bias from targeting-induced reverse causality.
} 
20 percent smaller two years after the marginal fine relative to one year after the marginal fine.

The third row of columns (1) - (4) of Table 3 indicates that facilities' discharge ratios also declined significantly following fines on other facilities in the same state but in a different industry. Results reported in the third row indicate that TSS discharge ratios fell by 0.6 to 1.1 percentage points in the year following the marginal fine on other facilities in the same state but in different industry, around a 2 to 4 percent overall reduction relative to the mean. As indicated in the fourth row, on average, general deterrence effects from fines in the same state but different industry appear to decay rapidly (in this case, to zero after one year).

The fifth and six rows of Table 3 in columns (1) - (4) indicate that facilities' average discharge ratios did not change in a statistically significant fashion following fines on other facilities in the same industry but located in a different regulatory jurisdiction (state). Point estimates imply, however, that TSS discharge ratios increased by 0.1 to 0.4 percentage points in the year following the marginal fine on other facilities in the same industry but different states. These point estimates translate into a roughly 0.5 to 1.5 percent rise in relative to the mean discharge ratio.

Columns (5) - (8) of Table 3 show results from analyses with enforcement spillover variables defined at the 2-digit industry level rather than the more detailed 3-digit level. Results are generally consistent with those reported in columns (1) - (4), but point estimates are smaller and somewhat noisier on average, consistent with expectations given less precisely defined industrial categories. The first and second rows of Table 3 columns (5) $-(8)$ indicate that facilities' average discharge ratios declined around 3 to 10 percent relative to 
mean levels in the year or two following the marginal fine on other facilities in the same state and industry. The coefficients in the third row suggest that facilities' average discharge ratio also declined following fines on others in the same state but different industry. Point estimates in rows 5 and 6 again provide suggestive, but still not statistically strong, evidence that average discharge ratios increased slightly following fines on facilities in the same industry but located in other states.

\section{B. Sensitivity}

All of our regressions contain facility fixed effects, and some contain industry-by-year fixed effects or state-by-year fixed effects to control for many types of common shocks. For specifications included in Table 3, we clustered standard errors at the state level to allow for any remaining within-state correlations. Table 4 explores sensitivity to clustering at other levels, including the industry level and facility level. Results are robust, and in some cases statistically stronger. We continue to find statistically significant or nearly statistically significant deterrence effects from fines on others in the same state and industry and from fines on others in the same state and different industry. Point estimates also consistently show pollution increases following the marginal fine on others in the same industry but in different states. These latter effects are statistically significant at conventional levels when standard errors are clustered at the industry-level.

The results reported in Table 3 examine the direct impacts of fines assessed to other facilities, consistent with our hypothesis that enforcement spillovers operate directly through the emissions choice. Although none of our theoretical channels require enforcement spillovers to operate directly on compliance outcomes, all effects could potentially impact statutory violations as 
well as pollution. We therefore replicate our analyses using TSS violations as the dependent variable, 1[violation ${ }_{i t}$ ]. Appendix Table A1 presents results. We find significant and large reductions (15-50 percent of baseline) in violation probabilities in the years following fines on other facilities in the same state and industry. We find modest, and occasionally statistically significant, reductions in violation probabilities in the year following a fine on other facilities in the same state and different industry. We find no consistent impact of fines on facilities located in different states on violation probabilities.

As a final sensitivity check, we replicate our analyses using a different water pollution measure as the outcome variable. Biochemical oxygen demand (BOD) is a measure of the organic matter in wastewater discharges. 303 of the original 491 sample facilities report BOD measures for the majority of our pollution periods; our sample consists of these 303 facilities. ${ }^{24}$ The distribution of BOD pollution in our data is very similar to TSS pollution. Appendix Table A2 presents results of the replication analysis. All statistically significant BOD results are consistent with the TSS results, but on average point estimates are smaller and noisier given the smaller and less diverse sample. Significant point estimates continue to suggest facilities' discharge ratios declined in the years following fines on other facilities in the same state and industry and in the same state and different industry. Point estimates continue to suggest that discharge ratios marginally increased relative to the mean following fines on others in the same industry but different states, and some of the coefficients are significant at conventional levels.

\footnotetext{
${ }^{24}$ To be precise, we observe BOD discharges for facilities using the five-day 20 degrees $C$ test indicated by EPA parameter 00310.
} 


\section{Interpreting empirical results}

Our empirical results are subject to several caveats. One possible threat to internal validity involves the use of self-reported pollution data. As noted, employees and managers face severe criminal penalties for intentional misreporting, and several forensic data explorations fail to reject the accuracy of self-reporting for the large CWA manufacturing facilities in our sample. Nevertheless, it remains possible that some of our detected enforcement spillovers reflect economic incentives to change reported pollution as well as economic incentives to change actual pollution. A second possible threat to internal validity is that our data do not allow us to identify parent company owners. This concern conservatively biases our two positive within-state enforcement spillover results towards zero, but it does raise the possibility that our negative within-industry/cross-state enforcement spillover result could be driven by parent firms shifting production from facilities in high enforcement states to facilities in low enforcement states. Although we would ideally separately identify production shifting within-parents from production shifting across-parents, we note that under plausible assumptions the equilibrium effects of enforcement shocks do not depend on ownership. ${ }^{25} \mathrm{~A}$ third possible threat to internal validity is time-varying endogeneity induced by omitted variables or reverse causality operating at the state or industry level. Again, this concern conservatively biases our two positive within-state enforcement spillover results towards zero. Moreover, in specifications with state-by-year or industry-by-year fixed effects, bias only arises if shocks are correlated with anomalous withinstate-year pollution variation or with anomalous within-industry-year pollution variation.

\footnotetext{
${ }^{25}$ We thank a conference discussant for pointing this out.
} 
Subject to the above caveats, we interpret our empirical results as consistent with our main theoretical predictions. Our first prediction asserts that facilities in the same regulatory jurisdiction but different industries will experience positive enforcement spillovers, so that penalties at facility A reduce emissions at facility B. We found empirically that a given facility's pollution declined around 2 to 4 percent the year following the marginal fine on other facilities in the same state but a different industry. Prediction 2 states that facilities in the same industry but different regulatory jurisdictions will experience negative enforcement spillovers, so that penalties at facility $A$ increase emissions at facility B. Empirical point estimates indicate that a given facility's pollution increased around 0.5 to 1.5 percent the year following the marginal fine on other facilities in the same industry but different states. Prediction 3 maintains that facilities in the same industry facing the same regulatory authority will experience positive enforcement spillovers provided regulatory channels dominate product market channels. We found empirically that a given facility's pollution declined around 9 to 11 percent following the marginal fine on other facilities in the same state and industry. This result is consistent with strong regulatory channels and weaker product market channels for large manufacturers in the CWA setting.

Empirical support for our more nuanced theoretical predictions is mixed. Prediction 2a states that enforcement spillovers for facilities in the same industry and jurisdiction will differ from spillovers for facilities in the same industry but different jurisdictions. This prediction implicitly assumes that strategic interactions among facilities within these two groups arising through the product market channel will be similar; the only difference therefore will be those attributable to the regulatory channel. We found empirically that spillovers 
were indeed statistically different at or around the 5 percent level for facilities in the same industry and state vs. the same industry and different state. ${ }^{26}$ The sign of the difference in coefficients is consistent with the theory.

Model prediction 1a asserts that enforcement spillovers for facilities in the same regulatory jurisdiction and industry will not equal spillovers for facilities in the same jurisdiction and different industries. Here the implicit assumption is that strategic interactions among facilities within these two groups stemming from the regulatory channel will be similar while those arising from the product market channel will differ. We found empirically that spillovers were statistically different at or around the 1 percent level for facilities in the same state and industry vs. the same state and different industry. ${ }^{27}$ However, the sign of the difference in coefficients is inconsistent with the theory. When facilities in the same industry produce strategic substitutes and all facilities in the same state face identical positive regulatory spillovers, the theory predicts larger positive total enforcement spillovers for facilities in the same state but different industries as compared to facilities in the same state and industry. Our empirical results find the opposite. A likely explanation is that regulatory channels themselves are stronger for facilities in the same industry; facilities may be most likely to be aware of, and/or most likely to extract signals from, enforcement actions levied towards facilities more like themselves. The weak empirical support for prediction 1a suggests the potential for future work to consider

\footnotetext{
${ }^{26}$ Regression coefficients in Table 3 columns (1) - (4) on 'fines on others 1-12 months ago, same state, same industry' and 'fines on others 1-12 months ago, different state, same industry' are statistically different from one another at or around the 5 percent level.

${ }^{27}$ Regression coefficients in Table 3 columns (1) - (4) on 'fines on others 1-12 months ago, same state, same industry' and 'fines on others 1-12 months ago, same state, different industry' are statistically different from one another at or around the 1 percent level.
} 
refinements of our empirical definitions of product market interactions and regulatory interactions.

\section{Conclusion}

Legal scholars have long asserted that penalties may spillover to enhance compliance and improve regulatory performance at non-sanctioned facilities (Braithwaite and Makkai 1991; Ayres and Braithwaite 1992, Thornton et al. 2005). A handful of economic studies have developed models and/or detected such enforcement spillovers empirically (Shimshack and Ward 2005; Gray and Shadbegian 2007; Heyes and Kapur 2009; Rincke and Traxler 2011). Nevertheless, the economic mechanisms driving enforcement spillovers have been incompletely understood.

This paper developed an analytic model that showed that enforcement spillovers can be driven by interactions in the regulatory environment, interactions in product markets, or both. A key insight is that enforcement spillovers previously attributed to regulator interaction or regulator reputation channels could also readily arise from output market interactions. Our model also generated several empirically refutable predictions.

We investigated enforcement spillovers empirically using pollution and penalty data from large manufacturers regulated under the US Clean Water Act. We found econometric results largely consistent with our theory. We detected large positive enforcement spillovers between facilities in the same regulatory jurisdiction. These positive spillovers were particularly large when facilities were in the same industry. Empirical point estimates also showed modest negative enforcement spillovers between facilities in different jurisdictions but the same industry. Taken collectively, empirical results provide evidence that enforcement spillovers in a real world regulatory context can be driven by regulator 
reputation mechanisms (as assumed in the small related literature) as well as by product market mechanisms (not previously emphasized in the existing literature).

In our analysis, the regulatory spillover channel appears strong relative to product market spillovers. Strong regulatory spillovers suggest that studies focusing on the effect of enforcement on the sanctioned facility alone understate the implications of enforcement for externalities within the same regulatory jurisdiction. However, one should be cautious in interpreting total spillover magnitudes. An enforcement action against a particular facility may have a pronounced spillover effect on another facility under the same regulatory jurisdiction while having a more subtle effect on a facility in the same product market but different jurisdiction. Total net effects, however, depend on the number of facilities in the regulatory jurisdiction and the number of facilities in other regulatory jurisdictions. Promising future work would tackle this issue more completely, but it is worth noting that the product market spillovers explored in this paper raise the possibility that enforcement actions could result in a "squeezing the balloon" effect - reducing emissions among facilities under the enforcement jurisdiction of the regulator but increasing emissions among facilities in the same industry but located in other jurisdictions. Such leakage could diminish the benefits of enforcement in some circumstances, and provide an additional argument for greater coordination of regulatory stringency across decentralized regulatory authorities. 


\section{REFERENCES}

Alm, J. (2012), 'Measuring, explaining, and controlling tax evasion: Lessons from theory, experiments, and field studies.' International Tax and Public Finance 19(1): 54-77.

Ayres, I., \& Braithwaite, J. (1992). Responsive regulation: Transcending the deregulation debate. Oxford University Press.

Baker, J. B. (2003). The case for antitrust enforcement. The Journal of Economic Perspectives, 17(4), 27-50.

Baylis, K., Fullerton, D., \& Karney, D. H. (2014). Negative leakage. Journal of the Association of Environmental and Resource Economists, 1(1), 51-73.

Beavis, Brian, and Ian Dobbs. 1987. "Firm behaviour under regulatory control of stochastic environmental wastes by probabilistic constraints." Journal of Environmental Economics and Management 14: 112-127.

Beavis, Brian, and Martin Walker. 1983. "Achieving Environmental Standards with Stochastic Discharges." Journal of Environmental Economics and Management 10: 103-111.

Becker, Gary. 1968. "Crime and punishment: An economic analysis". Journal of Political Economy 76: 169-217.

Bennear, Lori S., and Sheila M. Olmstead. "The impacts of the "right to know": Information disclosure and the violation of drinking water standards." Journal of Environmental Economics and Management 56.2 (2008): 117-130. 
Bentham, J. (1789), An Introduction to the Principles of Morals and Legislation. Clarendon Press.

Braithwaite, J., \& Makkai, T. (1991). Testing an expected utility model of corporate deterrence. Law and Society Review, 7-40.

Bronars, S. G., \& Lott, J. R. (1998). Criminal deterrence, geographic spillovers, and the right to carry concealed handguns. American Economic Review, 475-479.

Bulow, Jeremy I., John D. Geanakoplos, and Paul D. Klemperer. 1985.

"Multimarket Oligopoly: Strategic Substitutes and Complements." Journal of Political Economy 93(3): 488-511.

Bushnell, J. B., \& Mansur, E. T. (2011). Vertical targeting and leakage in carbon policy. The American Economic Review, 101(3), 263-267.

Bushnell, James B., Erin T. Mansur, and Celeste Saravia. 2008. "Vertical Arrangements, Market Structure, and Competition: An Analysis of Restructured U.S. Electricity Markets." American Economic Review 98(1): 237-266.

Carlough, L. (2004), 'General deterrence of environmental violation: A peek into the mind of the regulated public.' State of Oregon Department of Environmental Quality.

Chakraborti, Lopa, and Jay Shimshack. 2012. "The Accuracy of Self-Reported Pollution Data: Evidence from the Clean Water Act." Tulane University Economics Working Paper.

Cohen, M. (1998). Monitoring and Enforcement of Environmental Policy. International Yearbook of Environmental and Resource Economics, 3: 44-106. 
Dubin, J. A., M. J. Graetz, and L. L. Wilde (1987), 'Are we a nation of tax cheaters? New econometric evidence on tax compliance.' The American Economic Review 77(2): 240-245.

Dubin, J. A., M. J. Graetz, and L. L. Wilde (1990), 'The effect of audit rates on the federal individual income tax 1977-1986.' National Tax Journal 43(4): 395-409.

Earnhart, Dietrich. 2004. "Panel Data Analysis of Regulatory Factors Shaping Environmental Performance." The Review of Economics and Statistics 86(1): 391401.

Fowlie, M. L. (2009). Incomplete environmental regulation, imperfect competition, and emissions leakage. American Economic Journal: Economic Policy, 1(2), 72-112.

Gray, W. B., \& Deily, M. E. (1996). Compliance and enforcement: Air pollution regulation in the US steel industry. Journal of environmental economics and management, 31(1), 96-111.

Gray, W. B., \& Shadbegian, R. J. (2005). When and why do plants comply? paper mills in the 1980s. Law \& Policy, 27(2), 238-261.

Gray, Wayne B., and Ronald J. Shadbegian. 2007. "The Environmental Performance of Polluting Plants: A Spatial Analysis. Journal of Regional Science 47(1): 63-84.

Gray, Wayne B., and Jay P. Shimshack. 2011. "The Effectiveness of Environmental Monitoring and Enforcement: A Review of the Empirical Evidence. Review of Environmental Economics and Policy, 5(1), 3-24. 
Heyes, Anthony, and Sandeep Kapur. 2009. “Enforcement Missions: Targets vs Budgets." Journal of Environmental Economics and Management 58: 129-140.

Innes, R. and A.G. Sam (2008), 'Voluntary pollution reductions and the enforcement of environmental law: An empirical study of the 33/50 program.' Journal of Law and Economics 51: 271-296.

Jackson, H. E., \& Roe, M. J. (2009). Public and private enforcement of securities laws: Resource-based evidence. Journal of Financial Economics, 93(2), 207-238.

Kaplow, Louis and Steven Shavell. 1994. “Optimal law enforcement with selfreporting of behavior." Journal of Political Economy 102: 583-606.

LaPlante, Benoit, and Paul Rilstone. 1996. "Environmental inspections and emissions of the pulp and paper industry in Quebec." Journal of Environmental Economics and Management 31: 19-36.

Leeth, J. (2012). OSHA's role in promoting occupational safety and health. Foundations and Trends in Microeconomics. 7: 267-353.

Lyon, T. and J. Maxwell (2000), 'Voluntary approaches to environmental regulation: A survey.' In Economic Institutions and Environmental Policy, Maurizio Franzini and Antonio Nicita, Eds, 142-174.

McClelland, John D. and John K. Horowitz. 1999. "The Costs of Water Pollution Regulation in the Pulp and Paper Industry." Land Economics 75: 220-232.

Polinsky, A. M., \& Shavell, S. (2000). The Economic Theory of Public Enforcement of Law. Journal of Economic Literature, 38, 45-76. 
Rincke, J., \& Traxler, C. (2011). Enforcement spillovers. Review of Economics and Statistics, 93(4), 1224-1234.

Ruser, J. and R. Ruser (2010). The Economics of Occupational Safety and Health. Foundations and Trends in Microeconomics. 5: 301-354.

Sah, Raaj Kumar. 1991. "Social osmosis and patterns of crime." Journal of Political Economy 99: 1272-1295.

Segerson, Kathleen. 1988. "Uncertainty and Incentives for Nonpoint Pollution Control." Journal of Environmental Economics and Management 15: 87-98.

Shimshack, Jay P. 2014. "The economics of environmental monitoring and enforcement." Annu. Rev. Resour. Econ. 6(1), 339-360.

Shimshack, Jay P., and Michael B. Ward. 2005. "Regulator Reputation, Enforcement, and Environmental Compliance." Journal of Environmental Economics and Management 50: 519-540.

Shimshack, Jay P., and Michael B. Ward. 2008 "Enforcement and Overcompliance." Journal of Environmental Economics and Management 55: 90-105.

Stigler, G. J. (1970). The Optimum Enforcement of Laws. Journal of Political Economy, 526-536.

Thornton D., N. Gunningham, and R. Kagan (2005), 'General deterrence and corporate environmental behavior.' Law and Policy 27: 262-288. 
Uhlmann, D. (2009), 'Environmental crime comes of age: The evolution of criminal enforcement in the environmental regulatory scheme.' Utah Law Review 4: 1223-1252.

U.S. Environmental Protection Agency (1989), The Enforcement Management System: National Pollutant Discharge Elimination System. Washington, DC.

U.S. Environmental Protection Agency (1999). "Major findings of the CEIS review of the EPA's Permit Compliance System Database. Center for Environmental Information and Statistics. Washington, DC.

U.S. Government Accountability office (2009). "Clean Water Act: Longstanding Issues Impact EPA's and States' Enforcement Efforts." GAO-10-165T. U.S. Government Accountability Office. 
Figure 1: Simulation effects of increased regulatory pressure on facility $A$ on facility B's emissions and on total industry emissions for different values of $\boldsymbol{\beta}$

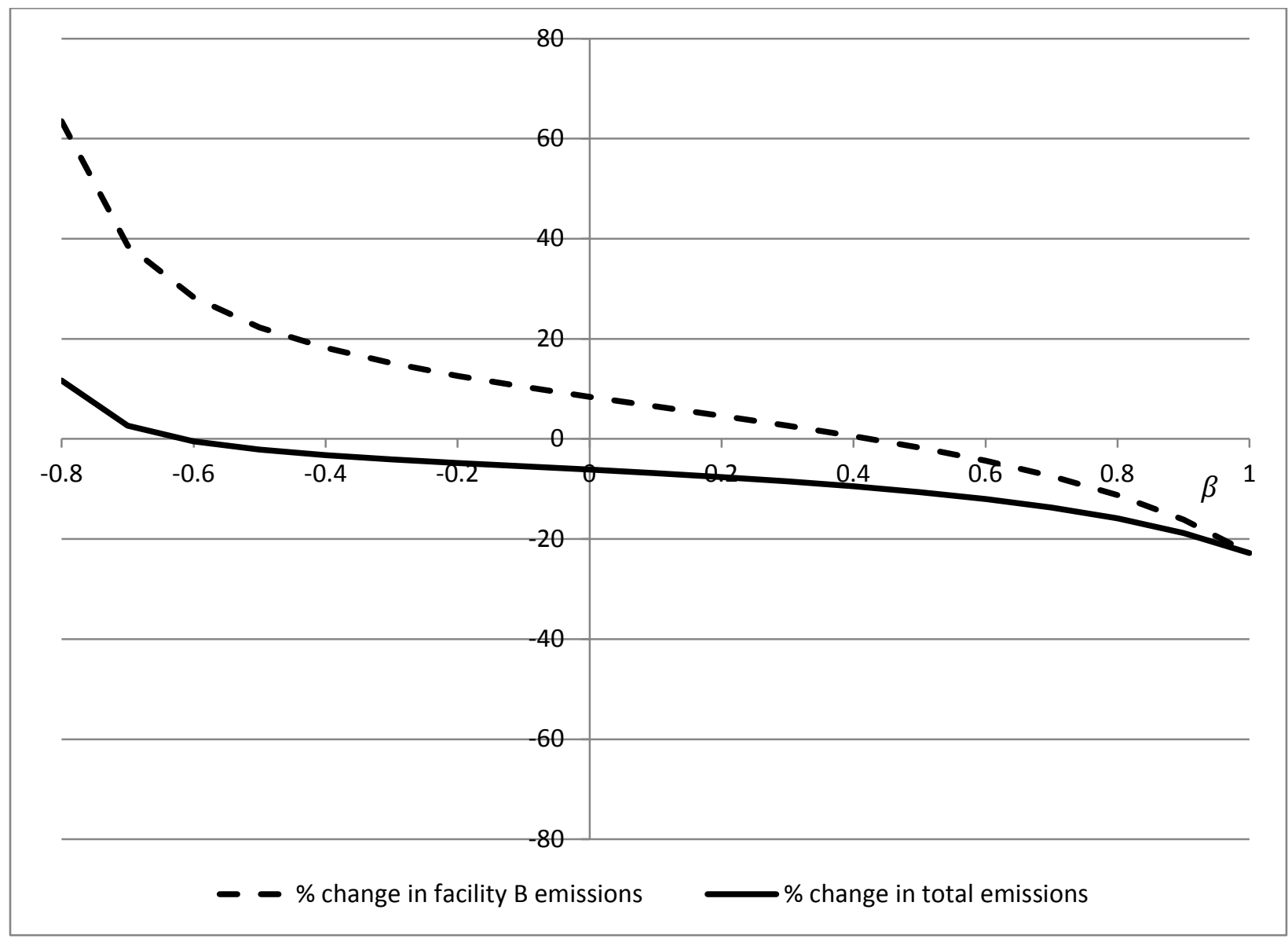

Note: The figure restricts the range of $\beta$ to be larger than -0.8 . Values of $\beta$ close to minus one seem implausible and yield negligible emissions costs for facility B. 
Figure 2. Sample facilities

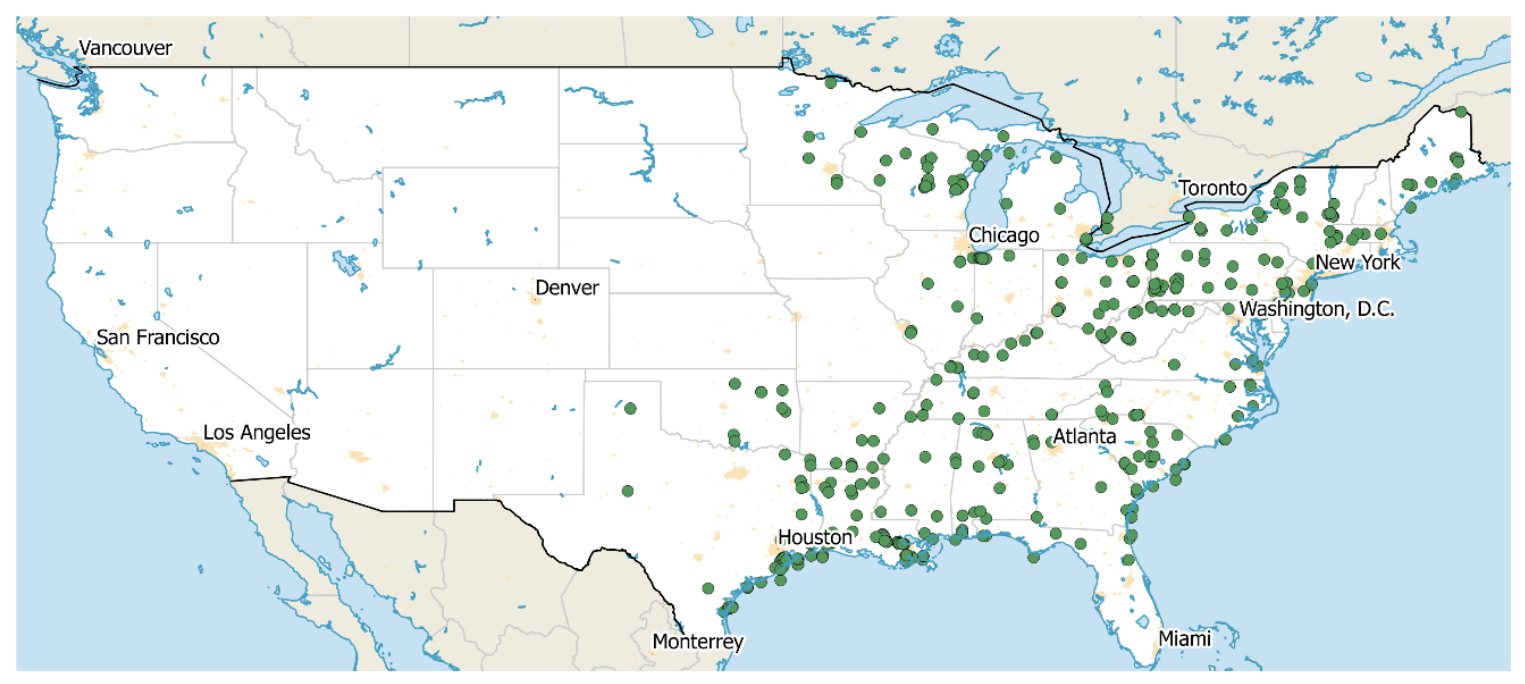


Table 1: Predicted net enforcement spillovers

\begin{tabular}{|c|c|c|c|c|}
\hline $\begin{array}{c}\text { Interaction in } \\
\text { regulatory } \\
\text { environment }\end{array}$ & $\begin{array}{l}\text { Interaction in } \\
\text { output market }\end{array}$ & $\begin{array}{l}\text { Overall enforcement } \\
\text { spillover }\end{array}$ & Sign of & $\frac{\partial e_{B}}{\partial \rho_{A}}$ \\
\hline None & None & Zero & 0 & \\
\hline None & Strategic substitutes & Negative & + & \\
\hline None & $\begin{array}{c}\text { Strategic } \\
\text { complements }\end{array}$ & Positive & - & \\
\hline Positive spillovers & None & Positive & - & \\
\hline Positive spillovers & Strategic substitutes & Ambiguous & $?$ & \\
\hline Positive spillovers & $\begin{array}{c}\text { Strategic } \\
\text { complements }\end{array}$ & Positive & - & \\
\hline $\begin{array}{l}\text { Negative } \\
\text { spillovers }\end{array}$ & None & Negative & + & \\
\hline $\begin{array}{l}\text { Negative } \\
\text { spillovers }\end{array}$ & Strategic substitutes & Negative & + & \\
\hline $\begin{array}{l}\text { Negative } \\
\text { spillovers }\end{array}$ & $\begin{array}{c}\text { Strategic } \\
\text { complements }\end{array}$ & Ambiguous & $?$ & \\
\hline
\end{tabular}


Table 2. Pollution and enforcement: summary statistics

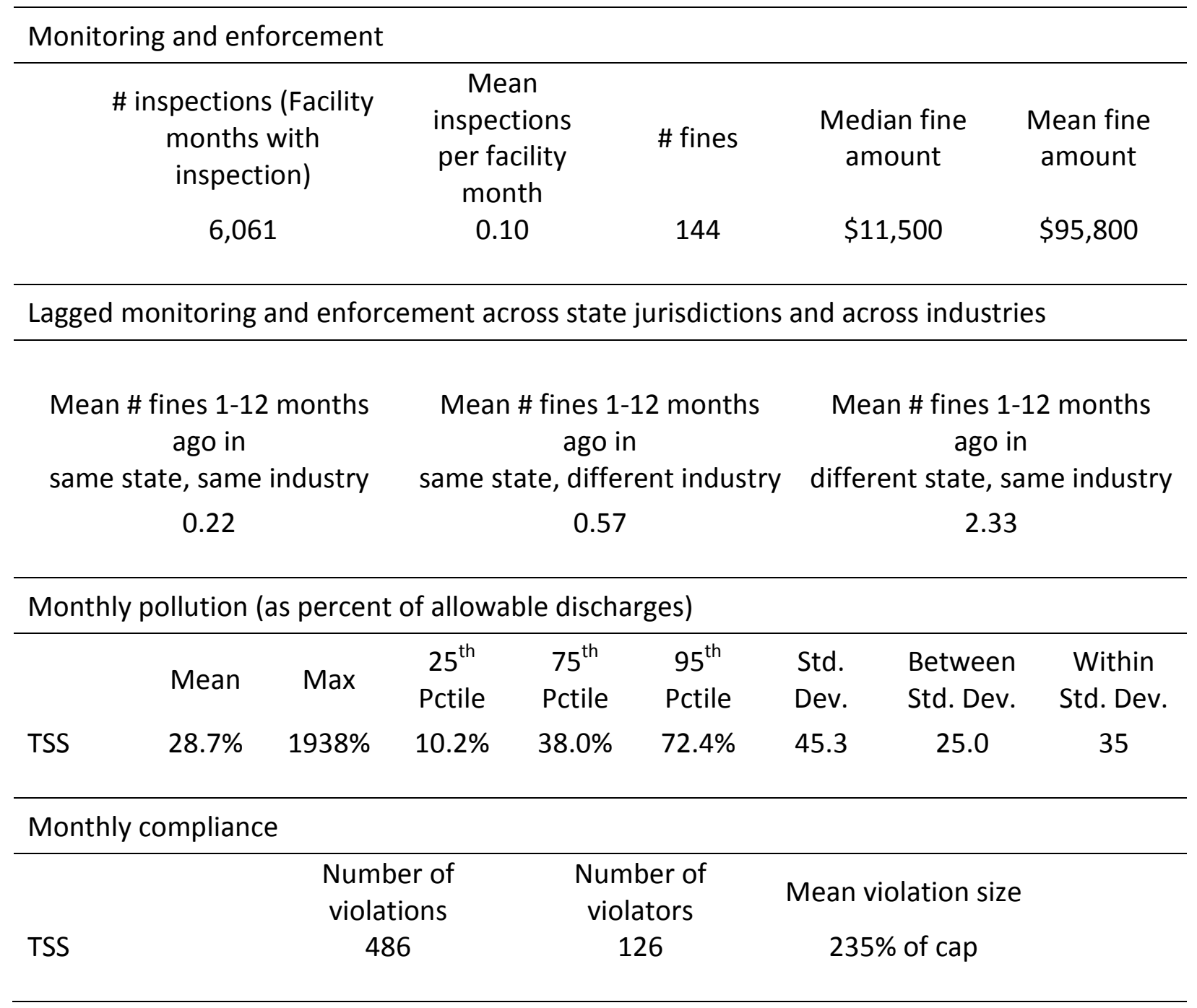


Table 3. Spillover effects of enforcement actions on total suspended solids discharges

\begin{tabular}{|c|c|c|c|c|c|c|c|c|}
\hline & \multicolumn{4}{|c|}{ Industry defined at 3-digit level } & \multicolumn{4}{|c|}{ Industry defined at 2-digit level } \\
\hline & (1) & (2) & (3) & (4) & (5) & (6) & (7) & (8) \\
\hline $\begin{array}{l}\text { Fines on others } 1-12 \text { months ago } \\
\text { same state, same industry }\end{array}$ & $\begin{array}{c}-2.612^{* *} \\
(1.117)\end{array}$ & $\begin{array}{c}-3.260 * * \\
(1.265)\end{array}$ & $\begin{array}{l}-3.054^{* *} \\
(1.212)\end{array}$ & $\begin{array}{l}-3.222^{*} \\
(1.618)\end{array}$ & $\begin{array}{c}-2.207 * * * \\
(0.556)\end{array}$ & $\begin{array}{c}-2.699 * * * \\
(0.632)\end{array}$ & $\begin{array}{c}-2.374 * * * \\
(0.596)\end{array}$ & $\begin{array}{c}-2.469 * * * \\
(0.865)\end{array}$ \\
\hline $\begin{array}{l}\text { Fines on others } 13-24 \text { months } \\
\text { ago same state, same industry }\end{array}$ & $\begin{array}{c}-2.282^{* *} \\
(1.032)\end{array}$ & $\begin{array}{c}-3.425^{* *} \\
(1.244)\end{array}$ & $\begin{array}{l}-2.633^{* *} \\
(1.046)\end{array}$ & $\begin{array}{l}-2.621^{* *} \\
(0.944)\end{array}$ & $\begin{array}{c}-1.061 * * * \\
(0.365)\end{array}$ & $\begin{array}{c}-2.039 * * * \\
(0.275)\end{array}$ & $\begin{array}{c}-1.402 * * * \\
(0.483)\end{array}$ & $\begin{array}{c}-1.303 * * * \\
(0.203)\end{array}$ \\
\hline $\begin{array}{c}\text { Fines on others } 1-12 \text { months ago } \\
\text { same state, different industry }\end{array}$ & $\begin{array}{c}-1.063 * * * \\
(0.348)\end{array}$ & $\begin{array}{c}-0.894 * * * \\
(0.266)\end{array}$ & $\begin{array}{l}-0.726^{*} \\
(0.400)\end{array}$ & $\begin{array}{l}-0.631^{*} \\
(0.346)\end{array}$ & $\begin{array}{l}-0.741 \\
(0.500)\end{array}$ & $\begin{array}{l}-0.588 \\
(0.421)\end{array}$ & $\begin{array}{l}-0.481 \\
(0.575)\end{array}$ & $\begin{array}{l}-0.324 \\
(0.385)\end{array}$ \\
\hline $\begin{array}{l}\text { Fines on others } 13-24 \text { months } \\
\text { ago same state, different industry }\end{array}$ & $\begin{array}{c}1.517 \\
(1.127)\end{array}$ & $\begin{array}{c}1.155 \\
(0.949)\end{array}$ & $\begin{array}{c}1.575 \\
(0.927)\end{array}$ & $\begin{array}{l}1.346 \\
(1.210)\end{array}$ & $\begin{array}{c}1.895 \\
(1.203)\end{array}$ & $\begin{array}{c}1.477 \\
(0.920)\end{array}$ & $\begin{array}{l}1.997 * \\
(1.047)\end{array}$ & $\begin{array}{c}1.557 \\
(1.222)\end{array}$ \\
\hline $\begin{array}{l}\text { Fines on others } 1-12 \text { months ago } \\
\text { different state, same industry }\end{array}$ & $\begin{array}{c}0.319 \\
(0.264)\end{array}$ & $\begin{array}{c}0.171 \\
(0.174)\end{array}$ & $\begin{array}{c}0.055 \\
(0.158)\end{array}$ & $\begin{array}{c}0.140 \\
(0.173)\end{array}$ & $\begin{array}{c}0.304 \\
(0.242)\end{array}$ & $\begin{array}{c}0.222 \\
(0.169)\end{array}$ & $\begin{array}{c}0.124 \\
(0.144)\end{array}$ & $\begin{array}{c}0.164 \\
(0.155)\end{array}$ \\
\hline $\begin{array}{l}\text { Fines on others } 13-24 \text { months ago } \\
\text { different state, same industry }\end{array}$ & $\begin{array}{c}0.389 \\
(0.313)\end{array}$ & $\begin{array}{c}0.199 \\
(0.220)\end{array}$ & $\begin{array}{c}0.292 \\
(0.367)\end{array}$ & $\begin{array}{c}0.171 \\
(0.185)\end{array}$ & $\begin{array}{c}0.184 \\
(0.194)\end{array}$ & $\begin{array}{c}0.130 \\
(0.147)\end{array}$ & $\begin{array}{c}0.056 \\
(0.310)\end{array}$ & $\begin{array}{c}0.066 \\
(0.132)\end{array}$ \\
\hline $\begin{array}{l}\text { Observations } \\
\text { Number of id }\end{array}$ & $\begin{array}{c}37,186 \\
415\end{array}$ & $\begin{array}{c}37,186 \\
415\end{array}$ & $\begin{array}{c}37,186 \\
415\end{array}$ & $\begin{array}{c}37,186 \\
415\end{array}$ & $\begin{array}{c}37,186 \\
415\end{array}$ & $\begin{array}{c}37,186 \\
415\end{array}$ & $\begin{array}{c}37,186 \\
415\end{array}$ & $\begin{array}{c}37,186 \\
415\end{array}$ \\
\hline
\end{tabular}

All specifications include lagged own inspections and fines, year fixed effects, season fixed effects, and facility fixed effects. Standard errors, clustered at the state level, are in parentheses. ${ }^{* * *} \mathrm{p}<0.01,{ }^{* *} \mathrm{p}<0.05,{ }^{*} \mathrm{p}<0.10$. The dependent variable is TSS pollution discharges, expressed as a percent of statutory limits. 
Table 4. Clustering choices

\begin{tabular}{|c|c|c|c|c|c|c|}
\hline & \multicolumn{3}{|c|}{ Industry defined at 3-digit level } & \multicolumn{3}{|c|}{ Industry defined at 2-digit level } \\
\hline & $\begin{array}{c}\text { Clustering } \\
\text { at State } \\
\text { Level } \\
(1)\end{array}$ & $\begin{array}{l}\text { Clustering } \\
\text { at Facility } \\
\text { Level } \\
(2)\end{array}$ & $\begin{array}{c}\text { Clustering } \\
\text { at } \\
\text { Industry } \\
\text { Level } \\
\text { (3) }\end{array}$ & $\begin{array}{c}\text { Clustering } \\
\text { at State } \\
\text { Level } \\
\text { (4) }\end{array}$ & $\begin{array}{l}\text { Clustering } \\
\text { at Facility } \\
\text { Level } \\
\\
(5)\end{array}$ & $\begin{array}{c}\text { Clustering } \\
\text { at } \\
\text { Industry } \\
\text { Level } \\
(6)\end{array}$ \\
\hline $\begin{array}{l}\text { Fines on others } 1-12 \text { months ago } \\
\text { same state, same industry }\end{array}$ & $\begin{array}{c}-2.612 * * \\
(1.117)\end{array}$ & $\begin{array}{c}-2.612 * * \\
(1.311)\end{array}$ & $\begin{array}{l}-2.612^{*} \\
(1.165)\end{array}$ & $\begin{array}{c}-2.207 * * * \\
(0.556)\end{array}$ & $\begin{array}{l}-2.207^{*} \\
(1.270)\end{array}$ & $\begin{array}{l}-2.207^{*} \\
(0.736)\end{array}$ \\
\hline $\begin{array}{l}\text { Fines on others } 13-24 \text { months } \\
\text { ago same state, same industry }\end{array}$ & $\begin{array}{c}-2.282 * * \\
(1.032)\end{array}$ & $\begin{array}{l}-2.282 \\
(1.427)\end{array}$ & $\begin{array}{l}-2.282^{*} \\
(0.921)\end{array}$ & $\begin{array}{c}-1.061 * * * \\
(0.365)\end{array}$ & $\begin{array}{l}-1.061 \\
(0.836)\end{array}$ & $\begin{array}{c}-1.061 * * * \\
(0.117)\end{array}$ \\
\hline $\begin{array}{l}\text { Fines on others } 1-12 \text { months ago } \\
\text { same state, different industry }\end{array}$ & $\begin{array}{c}-1.063^{* * *} \\
(0.348)\end{array}$ & $\begin{array}{l}-1.063 \\
(0.940)\end{array}$ & $\begin{array}{l}-1.063 \\
(0.594)\end{array}$ & $\begin{array}{l}-0.741 \\
(0.500)\end{array}$ & $\begin{array}{c}-0.741 \\
(0.771)\end{array}$ & $\begin{array}{l}-0.741 \\
(0.623)\end{array}$ \\
\hline $\begin{array}{c}\text { Fines on others } 13-24 \text { months ago } \\
\text { same state, different industry }\end{array}$ & $\begin{array}{c}1.517 \\
(1.127)\end{array}$ & $\begin{array}{c}1.517 \\
(1.006)\end{array}$ & $\begin{array}{c}1.517 \\
(1.110)\end{array}$ & $\begin{array}{c}1.895 \\
(1.203)\end{array}$ & $\begin{array}{c}1.895 \\
(1.284)\end{array}$ & $\begin{array}{c}1.895 \\
(1.129)\end{array}$ \\
\hline $\begin{array}{l}\text { Fines on others } 1-12 \text { months ago } \\
\text { different state, same industry }\end{array}$ & $\begin{array}{c}0.319 \\
(0.264)\end{array}$ & $\begin{array}{c}0.319 \\
(0.206)\end{array}$ & $\begin{array}{l}0.319^{*} \\
(0.152)\end{array}$ & $\begin{array}{c}0.304 \\
(0.242)\end{array}$ & $\begin{array}{c}0.304 \\
(0.239)\end{array}$ & $\begin{array}{l}0.304^{*} \\
(0.120)\end{array}$ \\
\hline $\begin{array}{c}\text { Fines on others } 13-24 \text { months ago } \\
\text { different state, same industry }\end{array}$ & $\begin{array}{c}0.389 \\
(0.313)\end{array}$ & $\begin{array}{c}0.389 \\
(0.262)\end{array}$ & $\begin{array}{c}0.389 \\
(0.274)\end{array}$ & $\begin{array}{c}0.184 \\
(0.194)\end{array}$ & $\begin{array}{c}0.184 \\
(0.151)\end{array}$ & $\begin{array}{c}0.184 \\
(0.143)\end{array}$ \\
\hline $\begin{array}{l}\text { Observations } \\
\text { Number of id }\end{array}$ & $\begin{array}{c}37,186 \\
415\end{array}$ & $\begin{array}{c}37,186 \\
415\end{array}$ & $\begin{array}{c}37,186 \\
415\end{array}$ & $\begin{array}{c}37,186 \\
415\end{array}$ & $\begin{array}{c}37,186 \\
415\end{array}$ & $\begin{array}{c}37,186 \\
415\end{array}$ \\
\hline
\end{tabular}

All specifications include lagged own inspections and fines, year fixed effects, season fixed effects, facility fixed effects, and facility-specific trends. Standard errors, clustered at the state level, are in parentheses. ${ }^{* *} p<0.01,{ }^{* *} p<0.05,{ }^{*} p<0.10$. The dependent variable is TSS pollution discharges, expressed as a percent of statutory limits. 


\section{Appendix Table A1. Robustness: Violations as the dependent variable}

\begin{tabular}{|c|c|c|c|c|c|c|}
\hline & \multicolumn{3}{|c|}{ Industry defined at 3-digit level } & \multicolumn{3}{|c|}{ Industry defined at 2-digit level } \\
\hline & $\begin{array}{l}\text { Linear } \\
\text { Prob. } \\
\text { (1) }\end{array}$ & $\begin{array}{l}\text { Linear } \\
\text { Prob. } \\
\text { (2) }\end{array}$ & $\begin{array}{l}\text { Cond. } \\
\text { Logit } \\
\text { (3) }\end{array}$ & $\begin{array}{c}\text { Linear } \\
\text { Prob. } \\
\text { (4) }\end{array}$ & $\begin{array}{l}\text { Linear } \\
\text { Prob. } \\
\text { (5) }\end{array}$ & $\begin{array}{l}\text { Cond. } \\
\text { Logit } \\
(6)\end{array}$ \\
\hline $\begin{array}{l}\text { Fines on others } 1-12 \text { months ago } \\
\text { same state, same industry }\end{array}$ & $\begin{array}{c}-0.320 * * \\
(0.137)\end{array}$ & $\begin{array}{c}-0.661 * * * \\
(0.099)\end{array}$ & $\begin{array}{c}-0.301 * * * \\
(0.113)\end{array}$ & $\begin{array}{c}-0.225^{* *} \\
(0.093)\end{array}$ & $\begin{array}{c}-0.391 * * * \\
(0.061)\end{array}$ & $\begin{array}{c}-0.211^{* * *} \\
(0.074)\end{array}$ \\
\hline $\begin{array}{c}\text { Fines on others } 13-24 \text { months ago } \\
\text { same state, same industry }\end{array}$ & $\begin{array}{l}-0.052 \\
(0.268)\end{array}$ & $\begin{array}{c}-0.514^{* * *} \\
(0.150)\end{array}$ & $\begin{array}{l}-0.098 \\
(0.187)\end{array}$ & $\begin{array}{l}-0.007 \\
(0.145)\end{array}$ & $\begin{array}{c}-0.288 * * * \\
(0.068)\end{array}$ & $\begin{array}{l}-0.034 \\
(0.128)\end{array}$ \\
\hline $\begin{array}{l}\text { Fines on others } 1-12 \text { months ago } \\
\text { same state, different industry }\end{array}$ & $\begin{array}{l}-0.140 * \\
(0.080)\end{array}$ & $\begin{array}{l}-0.064 \\
(0.065)\end{array}$ & $\begin{array}{l}-0.106 \\
(0.111)\end{array}$ & $\begin{array}{l}-0.121 \\
(0.134)\end{array}$ & $\begin{array}{l}-0.075 \\
(0.096)\end{array}$ & $\begin{array}{l}-0.095 \\
(0.109)\end{array}$ \\
\hline $\begin{array}{c}\text { Fines on others } 13-24 \text { months ago } \\
\text { same state, different industry }\end{array}$ & $\begin{array}{c}0.189 \\
(0.161)\end{array}$ & $\begin{array}{c}0.190 \\
(0.148)\end{array}$ & $\begin{array}{c}0.085 \\
(0.087)\end{array}$ & $\begin{array}{c}0.252 \\
(0.175)\end{array}$ & $\begin{array}{c}0.235 \\
(0.161)\end{array}$ & $\begin{array}{c}0.130 \\
(0.085)\end{array}$ \\
\hline $\begin{array}{l}\text { Fines on others 1-12 months ago } \\
\text { different state, same industry }\end{array}$ & $\begin{array}{l}-0.058 \\
(0.047)\end{array}$ & $\begin{array}{l}-0.052 \\
(0.039)\end{array}$ & $\begin{array}{l}-0.022 \\
(0.043)\end{array}$ & $\begin{array}{c}0.009 \\
(0.058)\end{array}$ & $\begin{array}{c}0.015 \\
(0.059)\end{array}$ & $\begin{array}{c}0.043 \\
(0.040)\end{array}$ \\
\hline $\begin{array}{c}\text { Fines on others } 13-24 \text { months ago } \\
\text { different state, same industry }\end{array}$ & $\begin{array}{c}0.071 \\
(0.054)\end{array}$ & $\begin{array}{c}0.066 \\
(0.065)\end{array}$ & $\begin{array}{c}0.077 \\
(0.060)\end{array}$ & $\begin{array}{c}0.007 \\
(0.037)\end{array}$ & $\begin{array}{c}0.022 \\
(0.050)\end{array}$ & $\begin{array}{c}0.059 \\
(0.047)\end{array}$ \\
\hline Facility-specific trends & YES & NO & NO & YES & NO & NO \\
\hline Observations & 37,186 & 37,186 & 11,453 & 37,186 & 37,186 & 11,453 \\
\hline Number of id & 415 & 415 & 126 & 415 & 415 & 126 \\
\hline
\end{tabular}

All specifications include lagged own inspections and fines, year fixed effects, season fixed effects, and facility fixed effects. Standard errors, clustered at the state level, are in parentheses. $* * * \mathrm{p}<0.01, * * \mathrm{p}<0.05, * \mathrm{p}<0.10$. The dependent variable is an indicator for a TSS pollution violation, where pollution exceeds allowable limits. Conditional logits do not include facilities that do not ever violate for TSS. 


\section{Appendix Table A2. Spillover effects of enforcement actions on biochemical oxygen demand (BOD) pollution}

\begin{tabular}{|c|c|c|c|c|}
\hline & \multicolumn{4}{|c|}{ Industry defined at 3-digit level } \\
\hline & $(1)$ & $(2)$ & (3) & $(4)$ \\
\hline Fines on others $1-12$ months ago & -0.310 & 0.283 & -0.519 & $-0.668 * *$ \\
\hline same state, same industry & $(0.423)$ & $(0.389)$ & $(0.571)$ & $(0.277)$ \\
\hline Fines on others $13-24$ months ago & -1.375 & -0.590 & $-1.889 *$ & -0.780 \\
\hline same state, same industry & $(0.839)$ & $(0.816)$ & $(0.931)$ & $(0.685)$ \\
\hline Fines on others $1-12$ months ago & $-0.384 * * *$ & $-0.428 *$ & $-0.325 * *$ & -0.279 \\
\hline same state, different industry & $(0.120)$ & $(0.229)$ & $(0.127)$ & $(0.267)$ \\
\hline Fines on others $13-24$ months ago & 0.069 & 0.285 & 0.103 & 0.364 \\
\hline same state, different industry & $(0.417)$ & $(0.266)$ & $(0.315)$ & $(0.260)$ \\
\hline Fines on others $1-12$ months ago & 0.156 & 0.078 & 0.022 & 0.234 \\
\hline different state, same industry & $(0.164)$ & (0.191) & $(0.173)$ & $(0.202)$ \\
\hline Fines on others $13-24$ months ago & $0.382 *$ & 0.253 & 0.083 & 0.352 \\
\hline different state, same industry & $(0.213)$ & $(0.211)$ & $(0.228)$ & (0.219) \\
\hline Facility-specific trends & YES & NO & YES & NO \\
\hline Industry-by-year fixed effects & NO & NO & YES & NO \\
\hline State-by-year fixed effects & NO & NO & NO & YES \\
\hline Observations & 27,107 & 27,107 & 27,107 & 27,107 \\
\hline Number of id & 303 & 303 & 303 & 303 \\
\hline
\end{tabular}




\section{Appendix: Proofs}

Proofs rely on the comparative static effects of a change in $\rho_{A}$. We derive these comparative static results before proceeding to the proofs. The elements of the Hessian matrix of second-order partial derivatives follows:

$$
\begin{aligned}
& h_{11} \equiv \frac{\partial^{2} \pi_{A}}{\partial q_{A}^{2}}=\frac{\partial^{2} R_{A}}{\partial q_{A}^{2}}-\frac{\partial^{2} C_{A}}{\partial q_{A}^{2}} \\
& h_{12} \equiv \frac{\partial^{2} \pi_{A}}{\partial q_{A} \partial e_{A}}=-\frac{\partial^{2} C_{A}}{\partial q_{A} \partial e_{A}}>0 \\
& h_{13} \equiv \frac{\partial^{2} \pi_{A}}{\partial q_{A} \partial q_{B}}=\frac{\partial^{2} R_{A}}{\partial q_{A} \partial q_{B}} \\
& h_{14} \equiv \frac{\partial^{2} \pi_{A}}{\partial q_{A} \partial e_{B}}=0 \\
& h_{21} \equiv \frac{\partial^{2} \pi_{A}}{\partial e_{A} \partial q_{A}}=-\frac{\partial^{2} C_{A}}{\partial e_{A} \partial q_{A}}=h_{12}>0 \\
& h_{22} \equiv \frac{\partial^{2} \pi_{A}}{\partial e_{A}^{2}}=-\frac{\partial^{2} C_{A}}{\partial e_{A}^{2}}-\frac{\partial^{2} F_{A}}{\partial e_{A}^{2}}<0 \\
& h_{23} \equiv \frac{\partial^{2} \pi_{A}}{\partial e_{A} \partial q_{B}}=0 \\
& h_{24} \equiv \frac{\partial^{2} \pi_{A}}{\partial e_{A} \partial e_{B}}=0 \\
& h_{31} \equiv \frac{\partial^{2} \pi_{B}}{\partial q_{B} \partial q_{A}}=\frac{\partial^{2} R_{B}}{\partial q_{B} \partial q_{A}} \\
& h_{32} \equiv \frac{\partial^{2} \pi_{B}}{\partial q_{B} \partial e_{A}}=0 \\
& h_{33} \equiv \frac{\partial^{2} \pi_{B}}{\partial q_{B}^{2}}=\frac{\partial^{2} R_{B}}{\partial q_{B}^{2}}-\frac{\partial^{2} C_{B}}{\partial q_{A B}^{2}} \\
& h_{34} \equiv \frac{\partial^{2} \pi_{B}}{\partial q_{B} \partial e_{B}}=-\frac{\partial^{2} C_{B}}{\partial e_{B} \partial q_{B}}>0
\end{aligned}
$$




$$
\begin{gathered}
h_{41} \equiv \frac{\partial^{2} \pi_{B}}{\partial e_{B} \partial q_{A}}=0 \\
h_{42} \equiv \frac{\partial^{2} \pi_{B}}{\partial e_{B} \partial e_{A}}=0 \\
h_{43} \equiv \frac{\partial^{2} \pi_{B}}{\partial e_{B} \partial q_{B}}==-\frac{\partial^{2} C_{B}}{\partial e_{B} \partial q_{B}}=h_{34}>0 \\
h_{44} \equiv \frac{\partial^{2} \pi_{B}}{\partial e_{B}^{2}}=-\frac{\partial^{2} C_{B}}{\partial e_{B}^{2}}-\frac{\partial^{2} F_{B}}{\partial e_{B}^{2}}<0
\end{gathered}
$$

We assume the matrix $\mathrm{H}$ is negative definite, which requires, $|H|>0$, $h_{11} h_{22}-h_{12} h_{21}>0$ and $h_{11}<0$. The determinant of $H$ is given by:

$$
\left(h_{11} h_{22}-h_{12} h_{21}\right)\left(h_{33} h_{44}-h_{34} h_{43}\right)-h_{13} h_{31} h_{22} h_{44} \text {. }
$$

Since the first term in parentheses and the last term are positive, $|H|>0$ requires $h_{33} h_{44}-h_{34} h_{43}>0$. This implies $h_{33}<0$ since $h_{44}<0$. The signs of $h_{13}$ and $h_{31}$ depend on whether the facilities produce strategic substitutes or complements.

Additional second-order partial derivatives required for the comparative static effects of a change in $\rho_{A}$ follow:

$$
\begin{gathered}
h_{1 \rho_{A}} \equiv \frac{\partial^{2} \pi_{A}}{\partial q_{A} \partial \rho_{A}}=0 \\
h_{2 \rho_{A}} \equiv \frac{\partial^{2} \pi_{A}}{\partial e_{A} \partial \rho_{A}}=-\frac{\partial^{2} F_{A}}{\partial e_{A} \partial \rho_{A}}<0 \\
h_{3 \rho_{A}} \equiv \frac{\partial^{2} \pi_{B}}{\partial q_{B} \partial \rho_{A}}=0 \\
h_{4 \rho_{A}} \equiv \frac{\partial^{2} \pi_{B}}{\partial e_{B} \partial \rho_{A}}=-\frac{\partial^{2} F_{B}}{\partial e_{B} \partial \rho_{A}} .
\end{gathered}
$$

If the facilities face positive (negative) regulatory spillovers, then $h_{4 \rho_{A}}<0$ $\left(h_{4 \rho_{A}}>0\right)$. By Cramer's rule, the comparative static effects of a change in $\rho_{A}$ are given by: 


$$
\begin{gathered}
\frac{\partial q_{A}}{\partial \rho_{A}}=\frac{1}{|H|}\left[h_{12} h_{2 \rho_{A}}\left(h_{33} h_{44}-h_{34} h_{43}\right)-h_{22} h_{13} h_{34} h_{4 \rho_{A}}\right] \\
\frac{\partial e_{A}}{\partial \rho_{A}}=\frac{1}{|H|}\left[h_{2 \rho_{A}}\left(-h_{11} h_{33} h_{44}+h_{11} h_{34} h_{43}+h_{13} h_{31} h_{44}\right)+h_{13} h_{21} h_{34} h_{4 \rho_{A}}\right] \\
\frac{\partial q_{B}}{\partial \rho_{A}}=\frac{1}{|H|}\left[h_{34} h_{4 \rho_{A}}\left(h_{11} h_{22}-h_{12} h_{21}\right)+h_{12} h_{31} h_{44} h_{2 \rho_{A}}\right] \\
\frac{\partial e_{B}}{\partial \rho_{A}}=\frac{1}{|H|}\left[-h_{33} h_{4 \rho_{A}}\left(h_{11} h_{22}-h_{12} h_{21}\right)+h_{12} h_{31} h_{43} h_{2 \rho_{A}}\right] .
\end{gathered}
$$

\section{Proof of Proposition 1:}

If the facilities produce strategic complements and face positive regulatory spillovers, then $h_{31}>0$ and $h_{4 \rho_{A}}<0$. Under these conditions, the term in brackets in the expression for $\frac{\partial q_{A}}{\partial \rho_{A}}$ is negative. Since $|H|>0, \frac{\partial q_{A}}{\partial \rho_{A}}<0$ in this case. In order to show $\frac{\partial e_{A}}{\partial \rho_{A}}<0$, first note that the last term in brackets, $h_{13} h_{21} h_{34} h_{4 \rho_{A}}$, is negative when $h_{31}>0$ and $h_{4 \rho_{A}}<0$. We now show that if $\mathrm{H}$ satisfies diagonal dominance, then the term in parentheses, $-h_{11} h_{33} h_{44}+$ $h_{11} h_{34} h_{43}+h_{13} h_{31} h_{44}$, is positive. The following inequalities hold under diagonal dominance:

(i) $\quad\left|h_{11}\right|>\left|h_{12}\right|+\left|h_{13}\right|$

(ii) $\quad\left|h_{22}\right|>\left|h_{21}\right|$

(iii) $\quad\left|h_{33}\right|>\left|h_{31}\right|+\left|h_{34}\right|$

(iv) $\quad\left|h_{44}\right|>\left|h_{43}\right|$

Multiply both sides of (iii) by $\left|h_{11}\right|\left|h_{44}\right|$ :

$$
\left|h_{11}\right|\left|h_{33}\right|\left|h_{44}\right|>\left|h_{11}\right|\left|h_{31}\right|\left|h_{44}\right|+\left|h_{11}\right|\left|h_{34}\right|\left|h_{44}\right| .
$$

The right-hand side of this expression exceeds the following:

$$
\left|h_{13}\right|\left|h_{31}\right|\left|h_{44}\right|+\left|h_{11}\right|\left|h_{34}\right|\left|h_{43}\right|
$$

since by (i), $\left|h_{11}\right|>\left|h_{13}\right|$, and by (iv), $\left|h_{44}\right|>\left|h_{43}\right|$. Combining equalities we have: 


$$
\begin{array}{r}
\left|h_{11}\right|\left|h_{33}\right|\left|h_{44}\right|>\left|h_{11}\right|\left|h_{31}\right|\left|h_{44}\right|+\left|h_{11}\right|\left|h_{34}\right|\left|h_{44}\right| \\
>\left|h_{13}\right|\left|h_{31}\right|\left|h_{44}\right|+\left|h_{11}\right|\left|h_{34}\right|\left|h_{43}\right| .
\end{array}
$$

This implies that the first term in parentheses, $-h_{11} h_{33} h_{44}$, which is positive, is larger in absolute value than the remaining two terms, $h_{11} h_{34} h_{43}+h_{13} h_{31} h_{44}$, which are negative. With $h_{2 \rho_{A}}<0$, the term in bracket is negative in the case of strategic complements and positive regulatory spillovers. Given $|H|>0$, $\frac{\partial e_{A}}{\partial \rho_{A}}<0$.

\section{Proof of Proposition 2:}

If the facilities produce strategic substitutes and face negative regulatory spillovers, then $h_{31}<0$ and $h_{4 \rho_{A}}>0$. The proof of this proposition is analogous to that of Proposition 1 but takes these sign differences into account.

\section{Proof of Corollary 1:}

Corollary 1 follows directly from comparing the relevant comparative static results.

\section{Proof of Proposition 3:}

When the two facilities have independent demands, the overall enforcement spillover effect is given by:

$$
\left.\frac{\partial e_{B}}{\partial \rho_{A}}\right|_{\frac{\partial^{2} F_{i}}{\partial e_{i} \partial \rho_{-i}} \neq 0, \frac{\partial^{2} R_{i}\left(q_{i}, q_{-i}\right)}{\partial q_{i} \partial q_{-i}}=0}=-\frac{1}{|H|}\left[h_{33} h_{4 \rho_{A}}\left(h_{11} h_{22}-h_{12} h_{21}\right)\right] .
$$

With independent demands and positive (negative) regulatory spillovers, the overall enforcement effect is negative (positive) so increased regulatory pressure on facility A decreases (increases) facility B's emissions. When demands are also interrelated, the overall enforcement spillover effect becomes: 


$$
\begin{aligned}
\left.\frac{\partial e_{B}}{\partial \rho_{A}}\right|_{\frac{\partial^{2} F_{i}}{\partial e_{i} \partial \rho_{-i}} \neq 0}, \frac{\partial^{2} R_{i}\left(q_{i}, q_{-i}\right)}{\partial q_{i} \partial q_{-i}} \neq 0 \\
\quad=\frac{1}{|H|}\left[-h_{33} h_{4 \rho_{A}}\left(h_{11} h_{22}-h_{12} h_{21}\right)+h_{12} h_{31} h_{43} h_{2 \rho_{A}}\right] .
\end{aligned}
$$

Therefore, $\left.\frac{\partial e_{B}}{\partial \rho_{A}}\right|_{\frac{\partial^{2} F_{i}}{\partial e_{i} \partial \rho_{-i}} \neq 0, \frac{\partial^{2} R_{i}\left(q_{i}, q_{-i}\right)}{\partial q_{i} \partial q_{-i}}=0} \neq\left.\frac{\partial e_{B}}{\partial \rho_{A}}\right|_{\frac{\partial^{2} F_{i}}{\partial e_{i} \partial \rho_{-i}} \neq 0, \frac{\partial^{2} R_{i}\left(q_{i}, q_{-i}\right)}{\partial q_{i} \partial q_{-i}} \neq 0}$.

\section{Proof of Proposition 4:}

When the two facilities have interrelated demands but no strategic interaction in the regulatory environment, the overall enforcement spillover effect is given by:

$$
\left.\frac{\partial e_{B}}{\partial \rho_{A}}\right|_{\frac{\partial^{2} F_{i}}{\partial e_{i} \partial \rho_{-i}}=0, \frac{\partial^{2} R_{i}\left(q_{i}, q_{-i}\right)}{\partial q_{i} \partial q_{-i}} \neq 0}=\frac{1}{|H|}\left[h_{12} h_{31} h_{43} h_{2 \rho_{A}}\right] .
$$

With no regulatory spillovers, if the facilities produce strategic complements (substitutes), then the general deterrence effect is positive (negative) so increased regulatory pressure on facility A decreases (increases) facility B's emissions. The overall enforcement spillover effect when they strategically interact in both settings is given in the proof of Proposition 3. Comparing the two expressions yields the result. 